\title{
Comprehensive Modeling of Temperature-Dependent Degradation Mechanisms in Lithium Iron Phosphate Batteries
}

\author{
M. Schimpe, $\oplus^{1, *, z}$ M. E. von Kuepach, ${ }^{1}$ M. Naumann, ${ }^{1}$ H. C. Hesse, ${ }^{1}$ K. Smith, ${ }^{2, * *}$ \\ and A. Jossen ${ }^{1}$ \\ ${ }^{1}$ Technical University of Munich (TUM), Institute for Electrical Energy Storage Technology (EES), 80333 Munich, \\ Germany \\ ${ }^{2}$ National Renewable Energy Laboratory, Transportation and Hydrogen Systems Center, Golden, Colorado 80401, \\ USA
}

\begin{abstract}
For reliable lifetime predictions of lithium-ion batteries, models for cell degradation are required. A comprehensive semi-empirical model based on a reduced set of internal cell parameters and physically justified degradation functions for the capacity loss is developed and presented for a commercial lithium iron phosphate/graphite cell. One calendar and several cycle aging effects are modeled separately. Emphasis is placed on the varying degradation at different temperatures. Degradation mechanisms for cycle aging at high and low temperatures as well as the increased cycling degradation at high state of charge are calculated separately. For parameterization, a lifetime test study is conducted including storage and cycle tests. Additionally, the model is validated through a dynamic current profile based on real-world application in a stationary energy storage system revealing the accuracy. Tests for validation are continued for up to 114 days after the longest parametrization tests. The model error for the cell capacity loss in the application-based tests is at the end of testing below $1 \%$ of the original cell capacity and the maximum relative model error is below $21 \%$.

(C) The Author(s) 2018. Published by ECS. This is an open access article distributed under the terms of the Creative Commons Attribution 4.0 License (CC BY, http://creativecommons.org/licenses/by/4.0/), which permits unrestricted reuse of the work in any medium, provided the original work is properly cited. [DOI: $10.1149 / 2.1181714 \mathrm{jes}]$

(cc) BY
\end{abstract}

Manuscript submitted October 11, 2017; revised manuscript received November 7, 2017. Published January 12, 2018. This was Paper 179 presented at the National Harbor, Maryland Meeting of the Society, October 1-5, 2017.

Today, stationary energy storage systems utilizing lithium-ion batteries account for the majority of new storage capacity installed. ${ }^{1}$ In order to meet technical and economic requirements, the specified system lifetime has to be ensured.

For reliable lifetime predictions, cell degradation models are necessary. Physicochemical models that include aging mechanisms are based on a detailed set of parameters which are often not readily available, computationally costly and require experimental parameterization of degradation rates. ${ }^{2-4}$ Instead, purely empirical models can be parameterized without knowledge of internal cell setup through extensive testing. Several purely empirical studies capture calendar aging ${ }^{5,6}$ or cycle aging ${ }^{7,8}$ without evaluating interdependencies. Through superposition, some empirical model approaches combine calendar and cycle aging ${ }^{9-12}$ but tend to neglect the temperature dependence of the cycle aging mechanisms and are prone to extrapolation errors due to the utilized mathematical functions.

Due to the limited knowledge about degradation mechanisms, empirically based models conventionally lump multiple degradation effects into single functions. This leads to the aforementioned prediction errors when deviating from the parameterization test conditions. E.g. for cycle aging, Waldmann et al. reported a transition of dominating aging mechanisms at $25^{\circ} \mathrm{C} . .^{13}$ The aging for temperatures above $25^{\circ} \mathrm{C}$ was attributed to the solid-electrolyte interface (SEI) growth and cathode degradation, while below $25^{\circ} \mathrm{C}$ the aging was attributed to lithium plating. In fact, for an improved understanding of cell internal degradation, model development should aim for a separation of the degradation mechanisms wherever possible. The respective mechanisms can then be modeled through functions that are suitable for the degradation driving factors.

In this work, a comprehensive semi-empirical capacity loss model for lithium-ion cells is introduced. A novelty of the approach is that a reduced set of internal cell data, i.e. electrode half-cell potential curves, is integrated into the model development. Further, various capacity loss mechanisms for calendar and cycle aging are captured separately in an empirical, yet physically supported approach.

For parameterization through experimental data, a lifetime test study is conducted. Cell type and experimental parameters are in accordance with an application in stationary systems. Stationary systems

\footnotetext{
*Electrochemical Society Student Member.

**Electrochemical Society Member.

${ }^{\mathrm{z}}$ E-mail: michael.schimpe@tum.de
}

require a long lifetime in terms of cycles (e.g. thousands of cycles) and years of operation (e.g. 10-20 years) for economic viability. ${ }^{14-16}$

Lithium iron phosphate $\left(\mathrm{LiFePO}_{4}\right)$ cell have shown capacity retention for more than 5,000 full cycles before usable capacities fall below $80 \%$, a benchmark number rendering them suitable for stationary applications. ${ }^{17}$

Consequently, the study and parameterization are based on a commercial $\mathrm{LiFePO}_{4}$ cell. The lifetime study is separated into parameterization and validation tests. Validation tests, derived from the application in a residential photovoltaic-battery system, are conducted subsequent to and distinguished from model parameterization and thus show the model performance in application-oriented conditions.

This paper is organized as follows. First, an overview of the experimental setup is given. The experimental results are then presented followed by the respective aging model. The calendar aging is discussed first, followed by the cycle aging. After summarizing the proposed model, the results are presented alongside with experimental data of parameterization test points and compared to points for model validation.

\section{Experimental}

For parameterization and evaluation of the proposed model, a lifetime test study is conducted. The experimental tests and procedures are briefly described.

The parameterization is based on a commercial 26650-format lithium iron phosphate cell (Sony US26650FTC1) designed for stationary applications. ${ }^{18}$ Datasheet parameters with notes for the respected voltage and current limits for this study are given in Table I.

The lifetime study is separated into parameterization and validation cycle tests. Validation tests are however excluded from model parameterization, to show the model performance in a dynamic realworld application scenario. Table II gives an overview of the experimental tests at various conditions. Storage tests capture parameterization and validation of calendar aging. The cycle tests conditions at various temperatures and different parameters for the current evaluate the cycle aging. The superscript numbers indicate the number of cells per test point, for statistical evaluation. The majority of test points only features a single cell, as a low variation $(<1 \%$ of original cell capacity for the capacity loss) for different cells at identical test points was observed in previous studies and is again confirmed in the results of this study. Therefore, the variable current profile tests featuring 


\begin{tabular}{|c|c|c|}
\hline Parameter & Value & Notes \\
\hline Nominal Voltage & $3.2 \mathrm{~V}$ & \\
\hline Nominal Capacity & $3000 \mathrm{mAh}$ & $\begin{array}{l}\text { Rated Capacity is } 2850 \mathrm{mAh} \text {. } \\
\text { Capacity } 3000 \mathrm{mAh} \text { is } \\
\text { denoted as nominal in this } \\
\text { study, as all tested cells have } \\
\text { this capacity at begin-of-life. }\end{array}$ \\
\hline $\begin{array}{l}\text { Charge Voltage } \\
\text { Discharge Voltage }\end{array}$ & $\begin{array}{c}3.60 \mathrm{~V} \pm 0.05 \mathrm{~V} \\
2.00 \mathrm{~V}\end{array}$ & $3.60 \mathrm{~V}$ is used in this study. \\
\hline $\begin{array}{l}\text { Continuous Max. } \\
\text { Charge Current }\end{array}$ & $2.85 \mathrm{~A}$ & $\begin{array}{l}\text { Continuous max. charge } \\
\text { current of } 1 \mathrm{C}-3.00 \mathrm{~A} \text { is used } \\
\text { in the study, based on the } \\
\text { begin-of-life capacity of } \\
3000 \text { mAh. }\end{array}$ \\
\hline $\begin{array}{l}\text { Continuous Max. } \\
\text { Discharge Current }\end{array}$ & $20 \mathrm{~A}$ & \\
\hline $\begin{array}{l}\text { Temperature } \\
\text { Range Charge }\end{array}$ & 0 to $+45^{\circ} \mathrm{C}$ & $\begin{array}{l}\text { Max. surface temperature is } \\
+60^{\circ} \mathrm{C} \text {. }\end{array}$ \\
\hline $\begin{array}{l}\text { Temperature } \\
\text { Range Discharge }\end{array}$ & -20 to $+60^{\circ} \mathrm{C}$ & $\begin{array}{l}\text { Max. surface temperature } \\
+80^{\circ} \mathrm{C}\end{array}$ \\
\hline
\end{tabular}

three cells for a single temperature were reduced after approximately 180 days of testing to two cells for the respective temperature. Test durations vary in the study - the longest test duration for parametrization is 234 days. Tests for validation are continued for up to 114 days beyond the longest parametrization tests to a total duration of 348 days.

Temperatures in the tests are $0^{\circ} \mathrm{C}, 10^{\circ} \mathrm{C}, 15^{\circ} \mathrm{C}, 25^{\circ} \mathrm{C}, 35^{\circ} \mathrm{C}, 45^{\circ} \mathrm{C}$ and $55^{\circ} \mathrm{C}$, to probe for varying degradation mechanisms. The storage tests are conducted at varying State of Charge (SOC) in steps of $12.5 \%$ from $0 \%$ to $100 \%$. The SOC is set through charging the cell with an amount of charge calculated with respective SOC and the current cell capacity, starting from a SOC of $0 \%$. Storage tests are performed at all temperatures except $0^{\circ} \mathrm{C}$, where the calendar aging is expected to be negligible.

Cycle aging parameterization is based on constant current (CC) full cycle tests at C-rates of $0.25 \mathrm{C}, 0.5 \mathrm{C}$, and $1 \mathrm{C}$, with and without Constant Voltage (CV)-phases at the end of charging. The chosen current rates cover the current range of the validation current profile, which is discussed below.

The cut-off current rate for the CC-CV tests is $\mathrm{C} / 10$. Constant Current $\mathrm{C}$-rates are identical for both charge and discharge. Both $\mathrm{CC}$ and $\mathrm{CC}-\mathrm{CV}$ tests operate over the full manufacturer-specified voltage range of $2.0 \mathrm{~V}$ to $3.6 \mathrm{~V}$.

For the model validation in application-oriented settings, a dynamic profile for application in a residential photovoltaic-battery system in Germany is tested. Test points are indicated in column Val of Table II. The profile data was provided by the Fraunhofer Institute for Solar Energy Systems from Project ESPEN - Potentials of

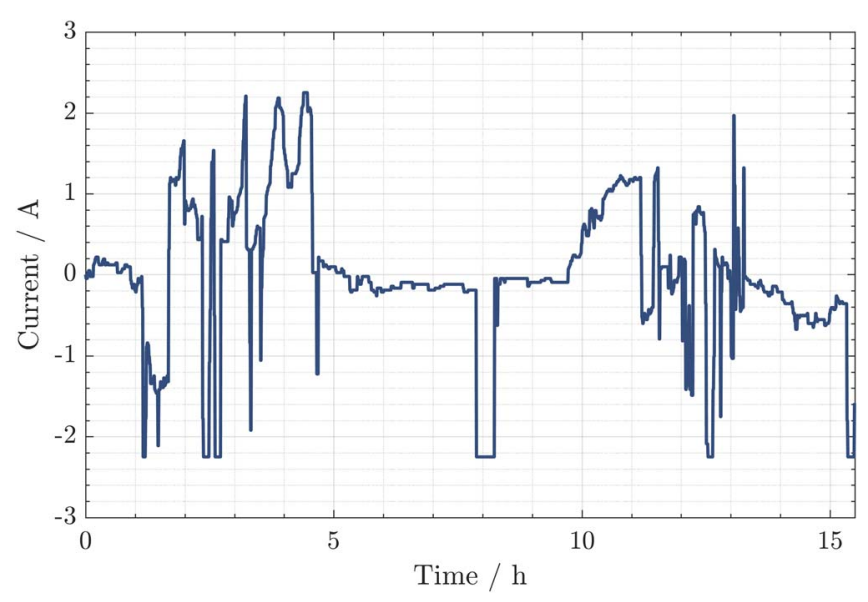

Figure 1. Current profile for validation tests representing a PV-residential application usage of the cell. Current direction for charging is positive. Profile data is based on ${ }^{19}$ and repetitively applied to the batteries tested with test condition Val.

Table III. Parameters of validation PV-residential current profile

Val. Data from Ref. 19.

\begin{tabular}{|c|c|c|c|}
\hline Parameter & Value & Parameter & Value \\
\hline Profile Duration & $15.5 \mathrm{~h}$ & Time Resolution & $60 \mathrm{~s}$ \\
\hline $\begin{array}{l}\text { Charge Throughput } \\
\text { per Cycle relative to } \\
\text { Nominal Cell } \\
\text { Capacity (Charge) }\end{array}$ & 1.56 & $\begin{array}{l}\text { Charge Throughput per } \\
\text { Cycle relative to Nominal } \\
\text { Cell Capacity (Discharge) }\end{array}$ & 1.56 \\
\hline $\begin{array}{l}\text { Time-averaged } \\
\text { C-Rate (Charge) }\end{array}$ & $+0.24 \mathrm{C}$ & $\begin{array}{c}\text { Time-averaged C-Rate } \\
\text { (Discharge) }\end{array}$ & $-0.17 \mathrm{C}$ \\
\hline Max. C-Rate (Charge) & $+0.75 \mathrm{C}$ & Max. C-Rate (Discharge) & $-0.75 \mathrm{C}$ \\
\hline Start SOC of Profile & $28 \%$ & Average SOC & $51.4 \%$ \\
\hline Min. SOC & $5.4 \%$ & Max. SOC & $80 \%$ \\
\hline
\end{tabular}

electrochemical storages in power grids in competition to further technologies and system solutions ${ }^{19}$ and scaled to the nominal cell capacity. Figure 1 shows the resulting current profile.

The profile is representative of a summer and a winter day. Rest durations are excluded for acceleration of the test results, leading to a profile duration of $15.5 \mathrm{~h}$. As the profile defines the battery current and features a coulombic efficiency of $100 \%$, the profile can be repeated permanently. The current profile features several current inversions, leading to varying cycle depths. It, therefore, supports the model validation in terms of the influence of the cycle depth on the capacity loss. Table III gives further parameters of the profile. All parameters relative to the cell capacity (Charge throughput, average/max. C-Rate, SOC values) are calculated with the nominal capacity of the cells (3 Ah).

Table II. Experimental test points of the lifetime study. Superscripts indicate the number of cells per test point. Column Val indicates validation test points based on dynamic-current application profiles.

\begin{tabular}{|c|c|c|c|c|c|c|c|c|c|c|c|c|c|c|c|c|}
\hline \multirow[b]{3}{*}{$\mathrm{T} /{ }^{\circ} \mathrm{C}$} & \multicolumn{9}{|c|}{ Storage } & \multicolumn{6}{|c|}{ Cycle } & \\
\hline & \multicolumn{9}{|c|}{ SOC } & \multicolumn{3}{|c|}{ CCC-Rate } & \multicolumn{3}{|c|}{ CC-CVC-Rate } & \\
\hline & 0 & 12.5 & 25 & 37.5 & 50 & 62.5 & 75 & 87.5 & 100 & 0.25 & 0.5 & 1 & 0.25 & 0.5 & 1 & Val \\
\hline 0 & & & & & & & & & & $X^{1}$ & $X^{1}$ & $\mathrm{X}^{2}$ & $X^{1}$ & $X^{1}$ & $X^{1}$ & \\
\hline 10 & $X^{1}$ & $X^{1}$ & $X^{1}$ & $\mathrm{X}^{1}$ & $X^{1}$ & $\mathrm{X}^{1}$ & $\mathrm{X}^{1}$ & $X^{1}$ & $X^{1}$ & $\mathrm{X}^{1}$ & $X^{1}$ & $\mathrm{X}^{3}$ & $X^{1}$ & $\mathrm{X}^{1}$ & $\mathrm{X}^{1}$ & $\mathrm{X}^{3}$ \\
\hline 15 & $\mathrm{X}^{1}$ & $X^{1}$ & $X^{1}$ & $\mathrm{X}^{1}$ & $\mathrm{X}^{1}$ & $\mathrm{X}^{1}$ & $\mathrm{X}^{1}$ & $\mathrm{X}^{1}$ & $\mathrm{X}^{1}$ & & & $\mathrm{X}^{3}$ & & & $\mathrm{X}^{1}$ & $\mathrm{X}^{3}$ \\
\hline 25 & $\mathrm{X}^{1}$ & $X^{1}$ & $\mathrm{X}^{1}$ & $\mathrm{X}^{1}$ & $\mathrm{X}^{1}$ & $\mathrm{X}^{1}$ & $\mathrm{X}^{1}$ & $\mathrm{X}^{1}$ & $\mathrm{X}^{1}$ & $\mathrm{X}^{1}$ & $\mathrm{X}^{1}$ & $\mathrm{X}^{3}$ & $\mathrm{X}^{1}$ & $\mathrm{X}^{1}$ & $\mathrm{X}^{1}$ & $\mathrm{X}^{3}$ \\
\hline 35 & $\mathrm{X}^{1}$ & $\mathrm{X}^{1}$ & $\mathrm{X}^{1}$ & $\mathrm{X}^{1}$ & $\mathrm{X}^{1}$ & $\mathrm{X}^{1}$ & $\mathrm{X}^{1}$ & $\mathrm{X}^{1}$ & $\mathrm{X}^{1}$ & & & $\mathrm{X}^{3}$ & & & $\mathrm{X}^{1}$ & $\mathrm{X}^{3}$ \\
\hline 45 & $\mathrm{X}^{1}$ & $X^{1}$ & $X^{1}$ & $\mathrm{X}^{1}$ & $\mathrm{X}^{1}$ & $X^{1}$ & $X^{1}$ & $\mathrm{X}^{1}$ & $\mathrm{X}^{1}$ & & & $X^{3}$ & & & $\mathrm{X}^{1}$ & $X^{3}$ \\
\hline 55 & $\mathrm{X}^{1}$ & $X^{1}$ & $\mathrm{X}^{1}$ & $\mathrm{X}^{1}$ & $\mathrm{X}^{1}$ & $X^{1}$ & $\mathrm{X}^{1}$ & $\mathrm{X}^{1}$ & $\mathrm{X}^{1}$ & $\mathrm{X}^{1}$ & $X^{1}$ & $\mathrm{X}^{1}$ & $\mathrm{X}^{1}$ & $\mathrm{X}^{1}$ & $\mathrm{X}^{1}$ & $X^{1}$ \\
\hline
\end{tabular}




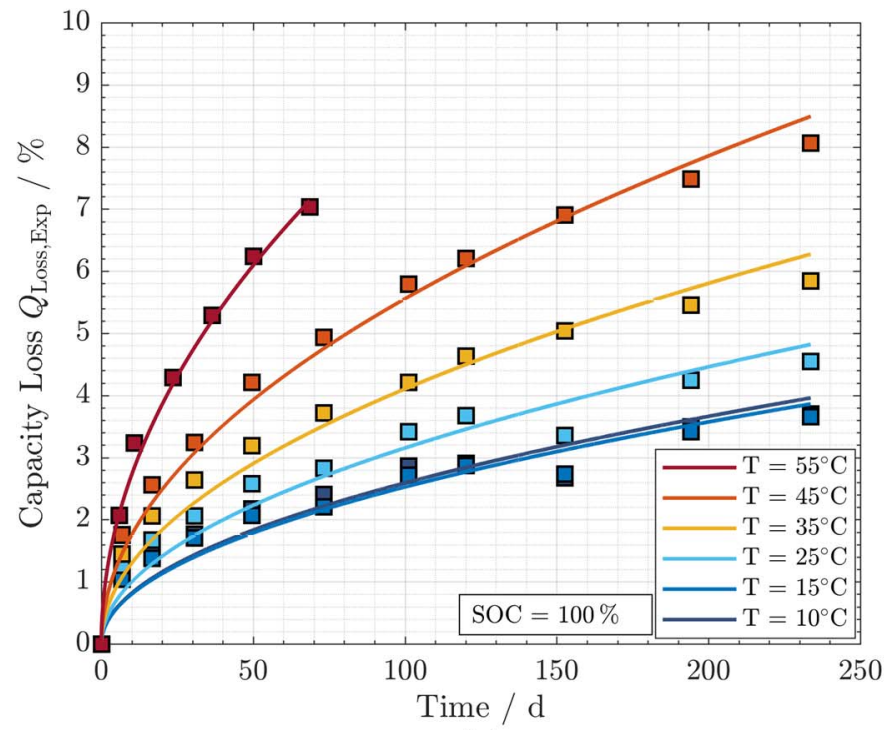

(a)

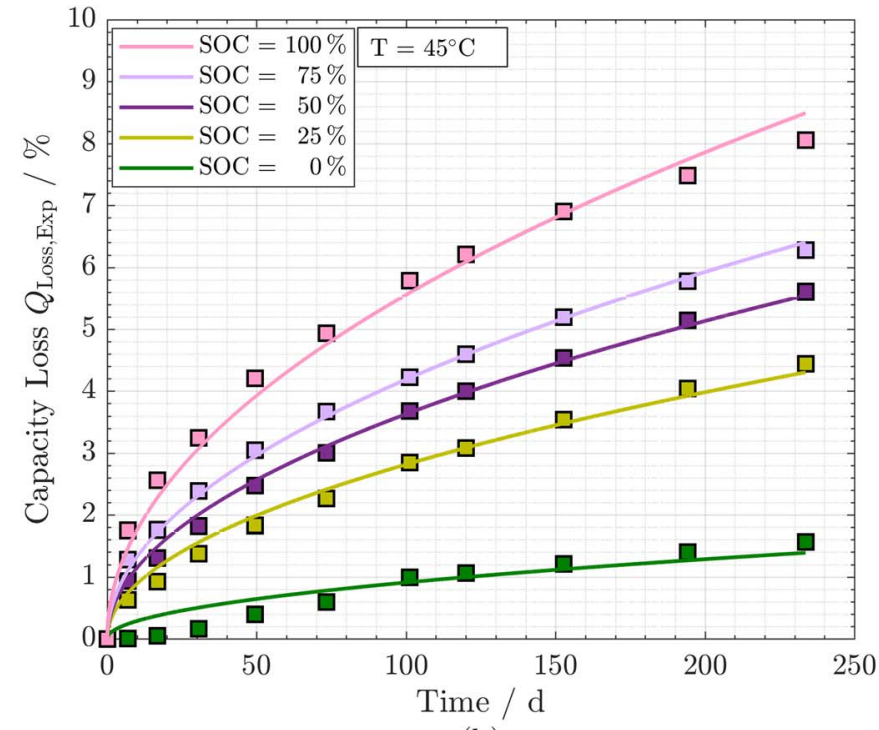

(b)

Figure 2. Capacity loss evaluation during storage: a) Influence of storage temperature at $S O C=100 \%$, b) Influence of State of Charge at $T=45^{\circ} \mathrm{C}$. Trend lines are fitted for each test condition for visualization.

Regular Reference Performance Tests (RPT) are performed at $25^{\circ} \mathrm{C}$ to allow for comparison between different test conditions. The first RPT is performed after one week of testing. The RPT frequency is increased with increased duration of the testing for cells, which did show only small changes between RPTs, to up to 6 weeks. As the cells show a high cycle stability at $25^{\circ} \mathrm{C}$, with less than $9 \%$ of capacity loss after 2800 full cycles at $1 \mathrm{C}$, the RPTs are expected to not significantly affect the results.

To accurately determine cell capacity regardless of impedance increases, two full charge-discharge $\mathrm{CC}-\mathrm{CV}$ cycles are conducted for measuring the cell capacity ( $\mathrm{CC}$ rate $1 \mathrm{C}$, current cut-off rate $\mathrm{C} / 50$ ), after an initial CC-CV discharge. For cell impedance, $\mathrm{R}_{\mathrm{DC}, 10 \mathrm{~s}}$ pulses and electrochemical impedance spectroscopy (EIS) tests are conducted, both at $S O C=50 \%$, after a relaxation time of $1 \mathrm{~h}$ and $12 \mathrm{~h}$ respectively.

In literature, typical limits for cell end of life (EOL) are a remaining capacity of $80 \%$ to the nominal value, corresponding to $20 \%$ of capacity loss, ${ }^{9,20}$ or an increase in cell impedance of $+50 \%$ to $+100 \% .^{9,21}$ Under such limits for EOL, the experiments reveal capacity loss to be the primary EOL criterion for all cells under test. E.g.: the test point $\mathrm{CC}$ cycling at ambient temperature of $45^{\circ} \mathrm{C}$ with $1 \mathrm{C}$ showed a capacity loss of $12 \%$ but only a moderate increase in the resistance $\mathrm{R}_{\mathrm{DC}, 10 \mathrm{~s}}$ of $4 \%$ after 2800 full equivalent cycles. Similarly, cells reaching $80 \%$ of remaining capacity also did not reach the EOL limit for impedance. Therefore, the capacity loss is the focus of this work.

For better visualization, the capacity loss in this work is not given through the value for the actual capacity (Unit: Ah), but normalized to the original cell capacity in the first RPT before the tests, $Q_{\text {Disch, } 0}$. The capacity loss of the cell, $Q_{\text {Loss,Exp,i }}$ in the RPT numbered $i$ is then calculated by averaging over two subsequent cycles in the RPT: $Q_{\text {Disch } i, 1}$ and $Q_{\text {Disch, } i, 2}$. As a reference, the first RPT of the cell before the tests, $Q_{\text {Disch,0 }}$ is used.

$$
Q_{\text {Loss,Exp,i }}=Q_{\text {Disch }, 0}-\left(Q_{\text {Disch }, i, 1}+Q_{\text {Disch }, i, 2}\right) / 2
$$

Tests are stopped when cell capacity drops below $80 \%$ of original capacity in the RPT. ${ }^{20,21}$ As the experimental results did not show a sudden increase in the rate of degradation, which is often described as non-linear aging that tends to appear below a cell capacity of $80 \%,{ }^{20}$ the proposed model does not include such changes in the degradation behavior and is not able to predict them either. The following model development, parameterization, and validation are thus limited to a cell capacity above $80 \%$ and do not include any mechanism for an increase in the rate of degradation.

\section{Calendar Aging}

The results of the storage experiments and their impact on the model are briefly discussed, followed by the definition of the calendar aging model.

Results of storage experiments.-Example results of the capacity loss during the storage experiments are shown in Figure 2. Data points represent the measurements taken in the RPT. A trend line is fitted according to Equation 2 and shown for each test condition for visualization purposes.

Figure 2a shows the influence of temperature through a comparison of test points for temperatures ranging from $10^{\circ} \mathrm{C}$ to $55^{\circ} \mathrm{C}$, with a constant $S O C=100 \%$. Higher temperature leads to a higher rate of capacity loss. The rate of capacity loss also decreases with time. Tests at $T=55^{\circ} \mathrm{C}$ were started later and the experiment is still in progress. Figure $2 \mathrm{~b}$ shows the influence of the SOC during storage through a comparison of test points for SOC from $0 \%$ to $100 \%$, with constant temperature $T=45^{\circ} \mathrm{C}$. Higher SOC is also accompanied by a higher rate of capacity loss.

The three described trends, decreasing rate of capacity loss over time (I), the influence of temperature (II) and SOC (III) are in good accordance with literature and have been previously described in more detail. $^{5,6,21}$ The mentioned trends all show a strong influence on the rate of capacity loss and are thus included in the calendar aging model.

Calendar aging model.-Calendar aging is described with the loss of cyclable lithium to the growth of the SEI at the anode over the life of the battery, which can trap lithium permanently. ${ }^{42-24}$ With increasing thickness and thus capacity loss, the growth decreases due to self-inhibited slow-down of the reaction. This decrease over time can be described with square-root dependence on time $t$, as used in existing models. ${ }^{25,26}$ The temperature and SOC dependence of the calendar aging mechanism is defined through the stress factor $k_{\mathrm{Cal}}$, which gives:

$$
Q_{\mathrm{L}, \mathrm{Cal}}(t)=k_{\mathrm{Cal}}(T, S O C) \cdot \sqrt{t}
$$

This equation for the calendar aging capacity loss is fitted to experimental data for a test with constant temperature and SOC, 


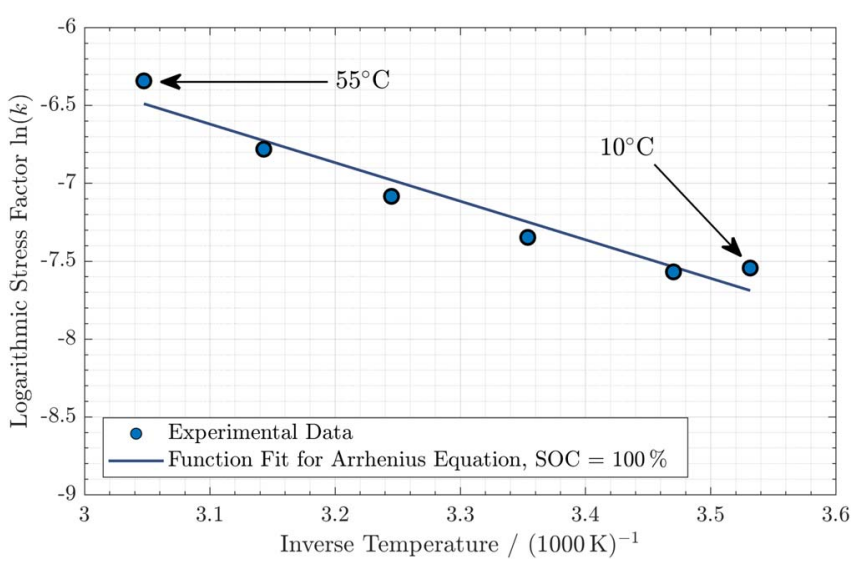

Figure 3. Arrhenius equation fit for temperature dependence of calendar stress factor. Data fitted for $S O C=100 \%$.

resulting in a condition-specific degradation stress factor. The trend lines in Figure 2 are fitted using this equation.

Assuming no correlation between the dependencies of capacity loss on temperature and SOC as commonly used, $, 6,11,25$ the stress factor is calculated with:

$$
k_{\mathrm{Cal}}(T, S O C)=k_{\mathrm{Cal}, \mathrm{Ref}} \cdot f(T) \cdot f(S O C)
$$

The calendar reference stress factor $k_{\mathrm{Cal}, \mathrm{Ref}}$ is defined and fitted for reference conditions at $T=25^{\circ} \mathrm{C}=298.15 \mathrm{~K}$ and $S O C=50 \%$ to a value of $k_{\mathrm{Cal}, \mathrm{Ref}}=k_{\mathrm{Cal}}(T=298.15 \mathrm{~K}, S O C=50 \%)=3.694$. $10^{-4} \mathrm{~h}^{-0.5}$.

Temperature dependence.-The temperature dependence of the calendar aging is modeled through the Arrhenius equation, as proposed by various authors: ${ }^{5,9,11,26}$

$$
k_{\mathrm{Cal}}(T, S O C=50 \%)=k_{\mathrm{Cal}, \mathrm{Ref}} \cdot \exp \left[\frac{-E_{\mathrm{a}, \mathrm{Cal}}}{R_{g}}\left(\frac{1}{T}-\frac{1}{T_{\mathrm{Ref}}}\right)\right]
$$

The parameter activation energy $E_{\mathrm{a}, \mathrm{Cal}}$, is determined by fitting the equation to the stress factors at $S O C=100 \%$, resulting in a value of $20592 \mathrm{~J} / \mathrm{mol}$. Constant parameters for the equation are the universal gas constant $R_{g}=8.314 \mathrm{~J} /(\mathrm{mol} \mathrm{K})$ and $T_{\text {Ref }}=298.15 \mathrm{~K}$. Figure 3 shows the comparison of model and experimental data, which indicates reasonable agreement for the fitting approach.

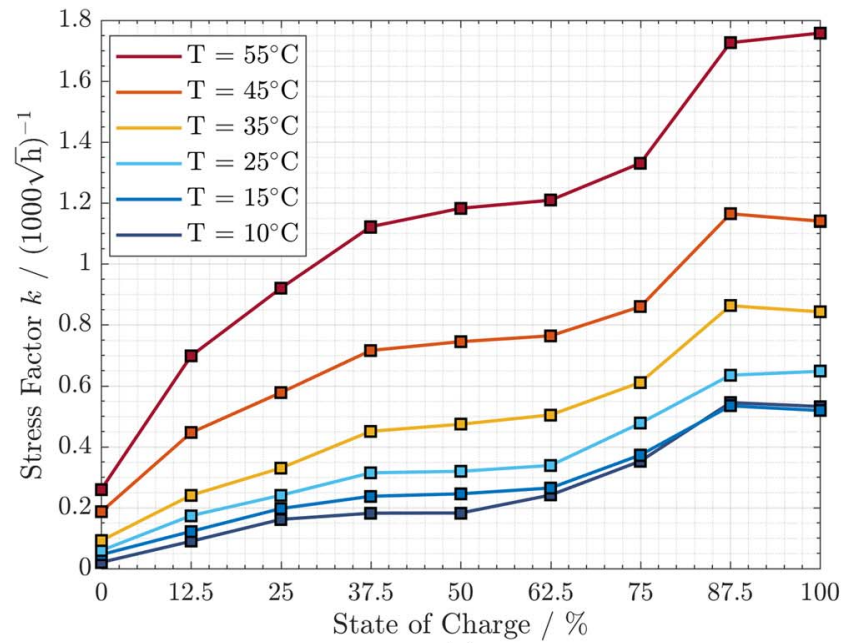

(a)
State of charge dependence.-The SOC dependence of the calendar aging mechanism is often fitted through polynomial ${ }^{6}$ or exponential functions ${ }^{5}$ using the SOC as an input variable. Other approaches include a function fit with the full-cell open circuit voltage as an input variable. ${ }^{9,21}$ Although fitting such model equations can provide good correlations, the models do not consider underlying physical mechanisms. Evaluating the stress factors over the state of charge, as shown in Figure 4a, leads to plateau regions for SOCs between $37.5 \%$ and $62.5 \%$, as well as between $87.5 \%$ and $100 \%$. No clear polynomial nor exponential trend can be identified, motivating a more sophisticated model formulation. Keil et al. attributed the plateau effects to the graphite electrode (anode) with a link to anode potentials. ${ }^{27}$

As the growth of SEI on the anode is driven by a potential difference, a model, which is based on a reformulated Tafel equation, is proposed.

The Tafel equation is:

$$
\Delta U=\frac{R_{g} \cdot T}{\alpha \cdot z \cdot F} \ln \frac{i}{i_{0}}
$$

Rearranging, setting $z=1$ for lithium-ions, and introducing reference values for current density $i$ and temperature $T$ gives:

$$
i=i_{\mathrm{Ref}} \cdot \exp \left[\frac{\alpha \cdot F \cdot \Delta U}{R_{g} \cdot T_{\mathrm{Ref}}}\right]
$$

The voltage difference $\Delta U$ is calculated from the anode open circuit potential $U_{\mathrm{a}}$, which is SOC dependent, and a reference potential $U_{\mathrm{a}, \operatorname{Ref}}$ :

$$
i=i_{\operatorname{Ref}} \cdot\left(\exp \left[\frac{\alpha \cdot F}{R_{g}}\left(\frac{U_{\mathrm{a}, \operatorname{Ref}}-U_{\mathrm{a}}(S O C)}{T_{\mathrm{Ref}}}\right)\right]\right)
$$

The current density is converted to the stress factor approach with an additional constant offset $k_{0}$ :

$$
\begin{aligned}
& k_{\mathrm{Cal}}\left(T=25^{\circ} \mathrm{C}, S O C\right) \\
& =k_{\mathrm{Cal}, \mathrm{Ref}} \cdot\left(\exp \left[\frac{\alpha \cdot \mathrm{F}}{R_{g}}\left(\frac{U_{\mathrm{a}, \mathrm{Ref}}-U_{\mathrm{a}}(S O C)}{T_{\mathrm{Ref}}}\right)\right]+k_{0}\right)
\end{aligned}
$$

This constant offset is required for proper fitting results and demands further investigations, as it is not included in the original Tafel equation.

Values for $U_{\mathrm{a}}$ are taken from Safari et al. ${ }^{28}$ Reformulation of the anode stoichiometry dependent data from Safari et al. to a function of the full-cell SOC is presented in the Appendix. Reference potential $U_{\mathrm{a}, \mathrm{Ref}}$ is set to $U_{\mathrm{a}}(S O C=50 \%)=0.123 \mathrm{~V}$. Fitting the equation parameters at $T_{\operatorname{Ref}}=298.15 \mathrm{~K}$ gives $\alpha=0.384, k_{0}=0.142$. The

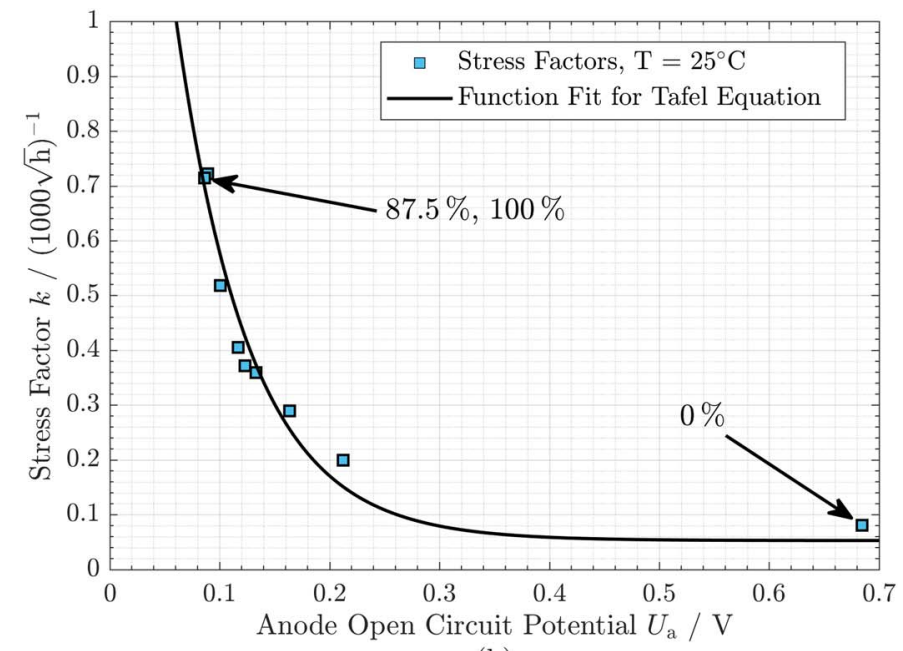

(b)

Figure 4. Modeling of State of Charge/anode open circuit potential dependence of calendar stress factor: a) Influence of SOC on stress factors, b) Tafel equation function fit for anode open circuit potential dependence of calendar stress factor. Data fitted for $T=25^{\circ} \mathrm{C}$. 


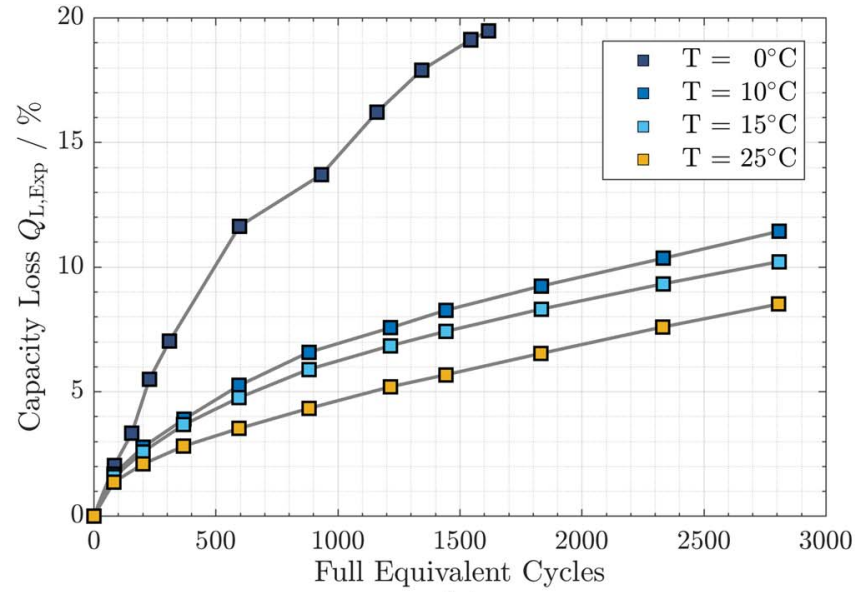

(a)

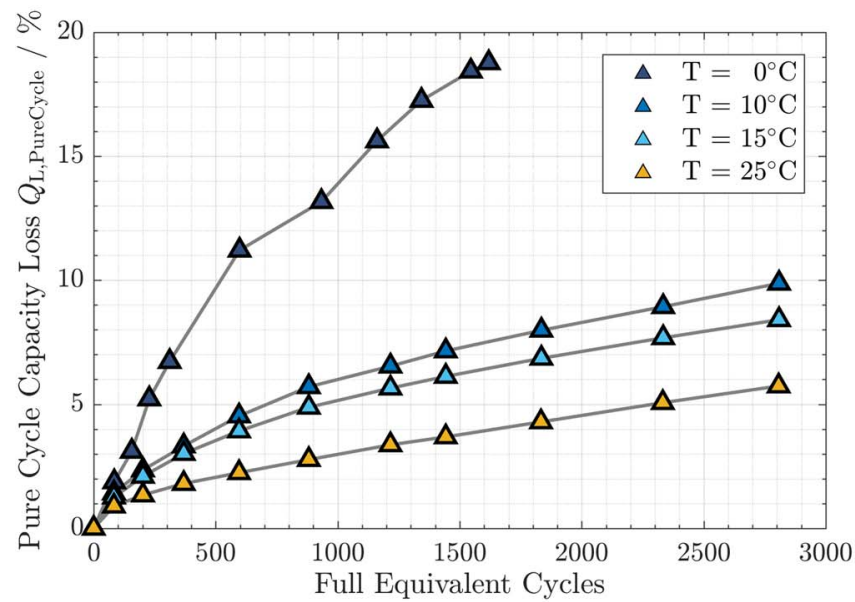

(c)

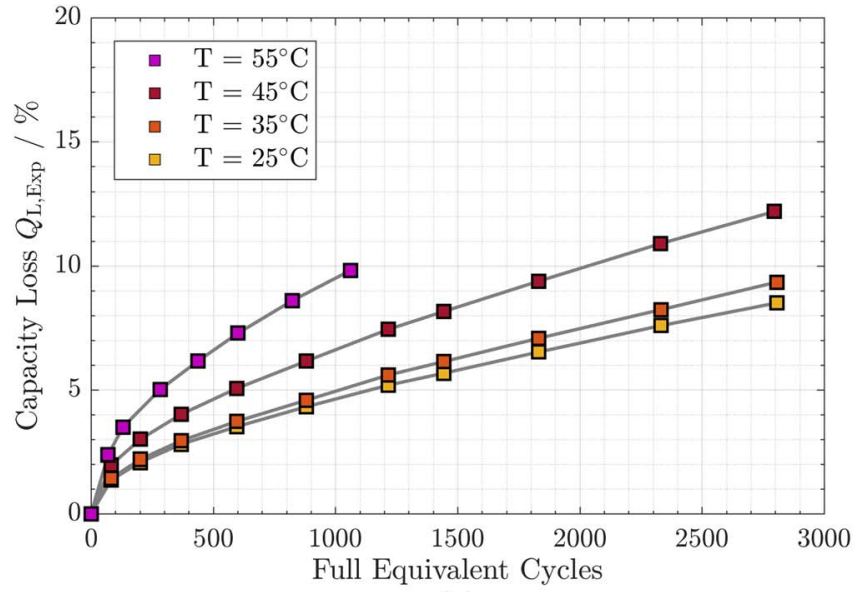

(b)

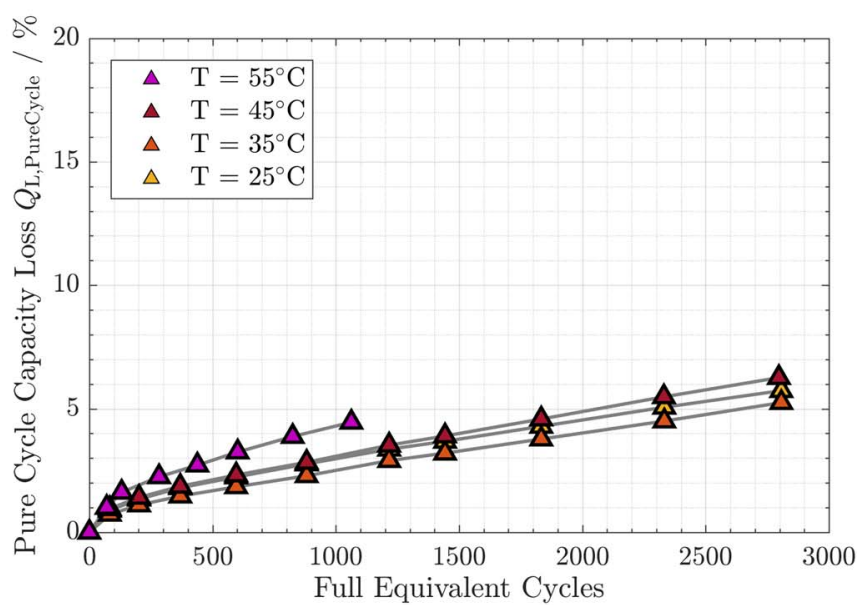

(d)

Figure 5. Temperature effect of capacity loss evaluation during $\mathrm{CC}$ cycle tests at $1 \mathrm{C}$ : a) Experimental capacity loss measurements at low temperatures $\left(0^{\circ} \mathrm{C}\right.$ to $\left.25^{\circ} \mathrm{C}\right)$, b) Experimental capacity loss measurements at high temperatures $\left(25^{\circ} \mathrm{C}\right.$ to $\left.55^{\circ} \mathrm{C}\right)$, c) Pure cycle capacity loss at low temperatures $\left(0^{\circ} \mathrm{C}\right.$ to $\left.25^{\circ} \mathrm{C}\right)$, d) Pure cycle capacity loss at high temperatures $\left(25^{\circ} \mathrm{C}\right.$ to $\left.55^{\circ} \mathrm{C}\right)$.

Faraday constant is given with $F=96485 \mathrm{C} / \mathrm{mol}$. Stress factors and the Tafel equation fit are shown over the anode open circuit potential in Figure $4 \mathrm{~b}$ for $T=25^{\circ} \mathrm{C}$. The coupling of the stress factor with the anode potential shows good agreement and reflects with high precision similar values for the stress factors at high SOC values, i.e. at the SOC of $87.5 \%$ and $100 \%$.

In summary, the stress factor due to calendar aging effects, as a function of temperature and storage SOC is obtained as follows:

$$
\begin{aligned}
k_{\mathrm{Cal}}(T, S O C)= & k_{\mathrm{Ca}, \mathrm{Ref}} \cdot \exp \left[\frac{-E_{\mathrm{a}, \mathrm{Cal}}}{R_{g}}\left(\frac{1}{T}-\frac{1}{T_{\mathrm{Ref}}}\right)\right] \\
& \cdot\left(\exp \left[\frac{\alpha \cdot \mathrm{F}}{R_{g}}\left(\frac{U_{\mathrm{a}, \mathrm{Ref}}-U_{\mathrm{a}}(S O C)}{T_{\mathrm{Ref}}}\right)\right]+k_{0}\right)
\end{aligned}
$$

\section{Cycle Aging}

The results of the cycling experiments and their implications for the model, separated for their dependence on the temperature, the current rate as well as on the state of charge, are briefly discussed followed by the cycle model definition.

Results of cycling experiments.-The measured capacity loss in the cycling experiments also reflects a capacity loss due to calendar aging, which occurs simultaneously.

Assuming that the calendar aging contributions to the cell aging follow the same mechanism for cells tested both under storage and cycling conditions, capacity loss from cycle-induced aging can be calculated as a superposition term to the calendar aging model outlined in the previous section.

After subtracting the model-based calendar aging, calculated with the average temperature measured in the experimental cycle tests which is higher than ambient temperature due to the heat produced by the cells - and at an average $S O C=50 \%$, from the measured capacity loss, the Pure Cycle capacity loss is obtained:

$$
Q_{\mathrm{L}, \text { Pure Cycle }}=Q_{\mathrm{L}, \text { Exp }}-Q_{\mathrm{L}, \text { Cal }}\left(T=\overline{T_{\text {Exp }}}, S O C=50 \%, t=t_{\text {Exp }}\right)
$$

This calculation neglects that the calendar aging is correlated nonlinear with temperature and SOC, as well as that the time-averaged SOC is not exactly $50 \%$. Calculations including the influence of the varying SOC and temperature in the cycle tests, however, show negligible influence on the model results and increase the efforts for parametrization significantly. Thus, the simplification based on the given average conditions is consequently used.

Temperature dependence.-Figure 5 shows the results for the CC cycle tests at $1 \mathrm{C}$ for various ambient temperatures over full equivalent cycles (FEC) of cycling ( 1 FEC $=6$ Ah throughput). Top figures show the experimental capacity loss, bottom figures the calculated pure cycle capacity loss. Low temperatures $\left(25^{\circ} \mathrm{C}\right.$ and lower) are shown on the left side, high temperatures $\left(25^{\circ} \mathrm{C}\right.$ and higher $)$ on the right side.

The experimental capacity loss is lowest for $T=25^{\circ} \mathrm{C}$. Lower as well as higher temperatures lead to a rise of the capacity loss. The 


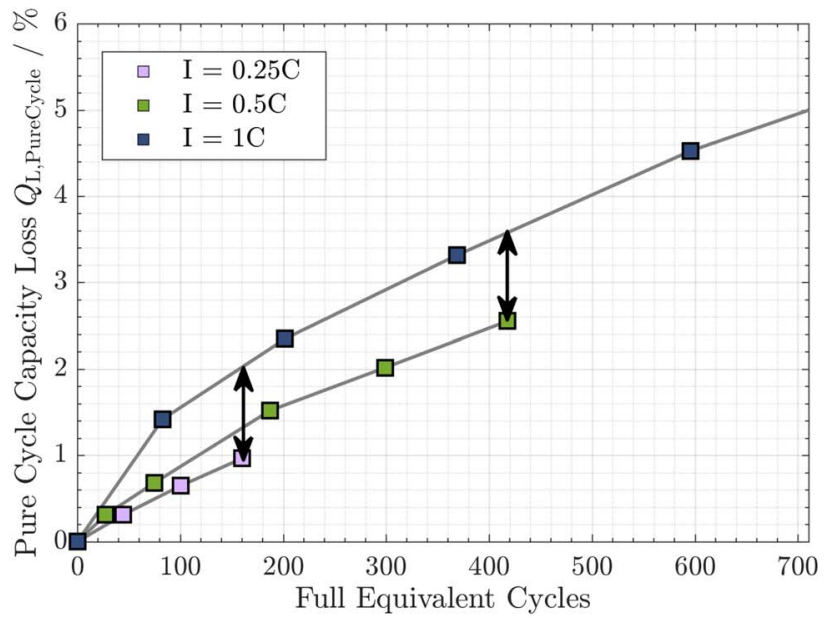

(a)

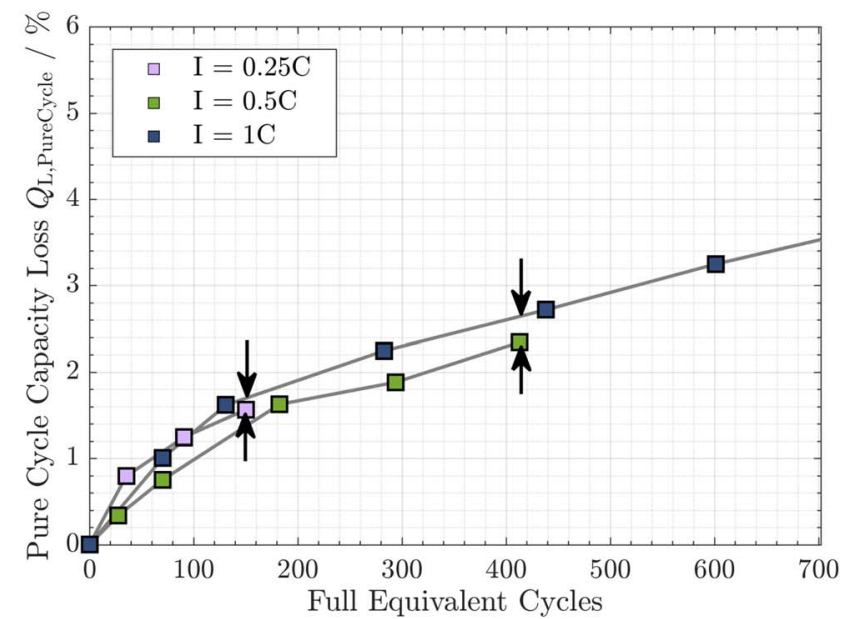

(b)

Figure 6. Current rate dependence of temperature effects: a) $T=10^{\circ} \mathrm{C}$, b) $T=55^{\circ} \mathrm{C}$. Arrows are added for visualization of strong/weak variation at low/high temperatures.

comparison between the experimental capacity loss and the pure cycle losses shows that the calendar aging factor that was subtracted has an increasing impact with increasing temperature. The pure cycle capacity loss has the minimum at $T=35^{\circ} \mathrm{C}$ and increases strongly at lower temperatures and slightly with higher temperatures. The data underlines the dominance of storage effects at high temperatures and that of pure cycling effects at lower temperatures. A strong temperature dependence of the pure cycle capacity loss is also identified.

The capacity loss at low-temperature cycling is often described in the literature as dominated by transport limitations, possibly lithium plating. ${ }^{29}$ Although we here and later in the text refer to transport limitations and lithium plating as possible mechanisms, no degradation analysis was conducted which could confirm or rebut this theory.

Cycling generally also mechanically disturbs the SEI, leading to fresh electrode surface area where new SEI can be formed. ${ }^{25}$ This cycling-induced SEI growth increases with higher temperature which may explain the increasing pure cycle capacity loss with higher temperatures. Both mechanisms, as well as the SEI growth during storage, reduce the capacity through the consumption of cyclable lithium. Assuming that these mechanisms both reduce the cyclable lithium in the battery cell are the dominating mechanisms under the respective operating conditions, the capacity loss can be modeled as a super- position of these factors. Further aging mechanisms, e.g., electrode material degradation, cannot be excluded but are difficult to deduce from full-cell test results.

Current rate dependence.-Figure 6 shows the pure cycle capacity loss for the $\mathrm{CC}$ cycle tests at current rates of $0.25 \mathrm{C}, 0.5 \mathrm{C}$, and $1 \mathrm{C}$ for a low-temperature $T=10^{\circ} \mathrm{C}$ (a) and a high temperature $T=55^{\circ} \mathrm{C}$ (b). At the low temperature, the pure cycle capacity loss increases with the current rate, whereas at the high temperature the pure cycle capacity loss is similar for all current rates tested. This indicates a strong correlation with current rate for the cycle aging mechanism at low temperatures only and none with mechanisms present at high temperatures.

This correlation supports the assumptions for the low-temperature aging mechanism: Capacity losses due to transport limitations, possibly lithium plating, are correlated with a high charge current rate. The high-temperature aging mechanism, however, shows no correlation with the current rate.

State of charge dependence.-Figure 7 shows the pure cycle capacity loss for the $\mathrm{CC}-\mathrm{CV}$ cycle tests at constant current rates of $0.5 \mathrm{C}$ and $1 \mathrm{C}$, for a low temperature $T=0^{\circ} \mathrm{C}$ (a) and a high temperature

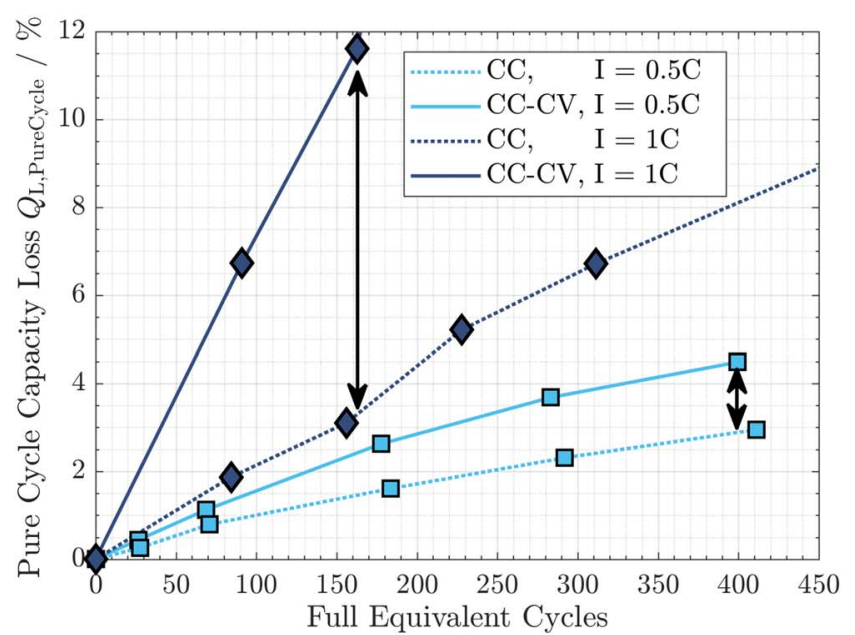

(a)

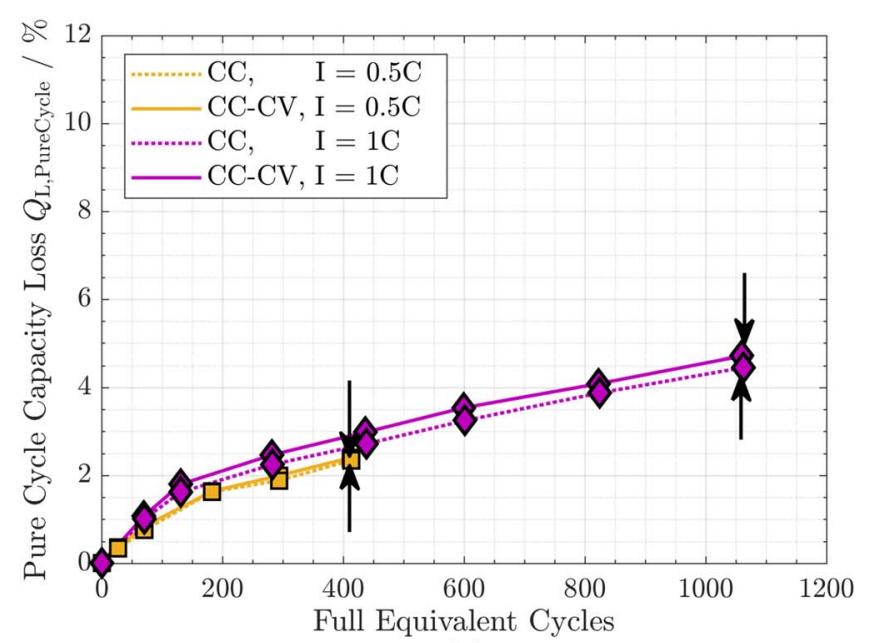

(b)

Figure 7. Influence of high SOC operation through CV-Phase at end of charge: a) $T=0^{\circ} \mathrm{C}$, b) $T=55^{\circ} \mathrm{C}$. Arrows are added for visualization of strong/weak variation at low/high temperatures. 


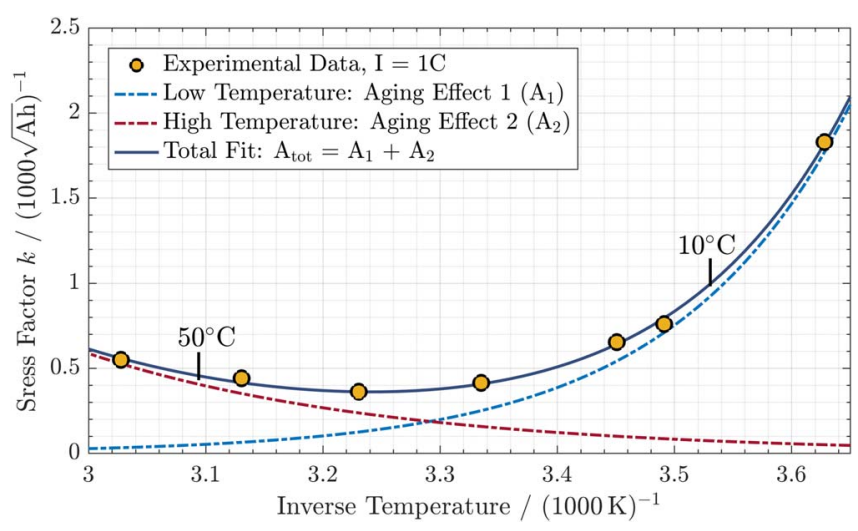

Figure 8. Superposition of two independent temperature dependent cycle aging capacity loss mechanisms for low temperature $\left(A_{1}\right)$ and high temperature $\left(A_{2}\right)$.

$T=55^{\circ} \mathrm{C}$ (b). Similar to the $\mathrm{CC}$ tests at low temperature, the pure cycle capacity loss increases with the current rate, but not for the high temperature tests. Comparing the $\mathrm{CC}$ and $\mathrm{CC}-\mathrm{CV}$ tests at low temperatures, the additional $\mathrm{CV}$ charging to a higher SOC leads to a strong increase of capacity loss, which is even more pronounced at the higher current rate. At high temperature, no difference between $\mathrm{CC}$ and $\mathrm{CC}-\mathrm{CV}$ tests is visible due to the kinetics enhancements due to the Arrhenius-type dependence of reaction rates on temperature.

This again supports the assumptions for the aging mechanisms due to transport limitations, mentionable the possibility of lithium plating, which occurs during charging with current rates at increasing/high state of charge. ${ }^{29}$ Finally, the aging mechanisms cannot be deduced definitely from the results and remain to be studied in future work.

Cycle aging model.-Based on the dependencies identified from the cells subjected to cycle aging, the cycle aging model is proposed. Three dominant mechanisms are defined:

- High Temperature $Q_{\mathrm{L}, \text { Cyc,High T }}$

- Low Temperature $Q_{\mathrm{L}, \text { Cyc,Low T }}$

- Low Temperature, High SOC $Q_{\mathrm{L}, \text { Cyc,Low T High SOC }}$

Following the previous assumption that all these aging mechanisms can be evaluated through superposition, the combined calendar and cycle aging model is proposed:

$$
\begin{gathered}
Q_{\mathrm{Loss}}=Q_{\mathrm{L}, \mathrm{Cal}}+Q_{\mathrm{L}, \mathrm{Cyc}} \\
Q_{\mathrm{Loss}}=Q_{\mathrm{L}, \mathrm{Cal}}+Q_{\mathrm{L}, \mathrm{Cyc}, \text { High T }}+Q_{\mathrm{L}, \mathrm{Cyc}, \text { Low T }}+Q_{\mathrm{L}, \mathrm{Cyc}, \text { Low T High SoC }}
\end{gathered}
$$

The cycle model does not include Depth of Discharge as an input variable, which is typically used with cycle counting algorithms and S-N curves (also known as Wöhler curve) for characterization of the higher stress of deep discharge cycles, e.g. reported for NMC-C cells by Schmalstieg et al. ${ }^{9}$ In fact, for lithium iron phosphate cells, the correlation of cyclic stress $(\mathrm{S})$ against the cycles to end of life $(\mathrm{N})$ was reported to be non-logarithmic previously. ${ }^{11}$

As such, the model proposed herein does not directly relate deeper cycles to increased capacity fade but calculates additional capacity loss for cells operating in high SOC regions due to the term attributed to lithium loss. Higher degradation during deeper cycles observed in our modeling approach is therefore attributed to the operation at higher SOC.

Temperature dependence.-The trend for the pure cycle capacity loss for high and low-temperature effects indicates a square root dependence on the charge throughput (see Figures $5 c-5 d$ ) and is subsequently discussed. Figure 8 shows the experimental stress factors and mechanisms for low temperature $\left(A_{1}\right)$, high temperature $\left(A_{2}\right)$, and their sum $\left(A_{\mathrm{tot}}=A_{1}+A_{2}\right)$, all fitted to the stress factors calculated from experimental data.

An increased SEI growth due to mechanical disturbance of the SEI, which is the assumed, although not proven, high-temperature cycling capacity loss mechanism, is not known to be specific to the current direction but with the cycling of the battery in general. It is correlated in the model with the total charge throughput, during both charging and discharging, $Q_{\text {Tot }}$. The corresponding stress factor $k_{\mathrm{Cyc}, \mathrm{High} \mathrm{T}}$ is implemented as a temperature dependent term:

$$
Q_{\mathrm{L}, \mathrm{Cyc}, \mathrm{High} \mathrm{T}}=k_{\mathrm{Cyc}, \mathrm{High} \mathrm{T}}(T) \cdot \sqrt{Q_{\mathrm{Tot}}}
$$

The low-temperature mechanism is implemented similarly, but with an additional current rate dependence. As the assumed mechanism for lithium loss occurs during charging; so the charge throughput in charge direction $Q_{\mathrm{Ch}}$ is chosen as input. The current rate dependence is also reflected in the model through the charge current $I_{\mathrm{Ch}}$ for the stress factor $k_{\text {Cyc,Low T }}$ :

$$
Q_{\mathrm{L}, \text { Cyc }, \text { Low T }}=k_{\text {Cyc,Low T }}\left(T, I_{\mathrm{Ch}}\right) \cdot \sqrt{Q_{\mathrm{Ch}}}
$$

Fitting the stress factors to reference conditions at $T_{\mathrm{Ref}}=298.15 \mathrm{~K}$ at $1 \mathrm{C}$ cycling gives $k_{\mathrm{Cyc}, \mathrm{High} \text { T,Ref }}=1.456 \cdot 10^{-4} \cdot \mathrm{Ah}^{-0.5}$ and $k_{\text {Cyc,Low T,Ref }}=4.009 \cdot 10^{-4} \cdot \mathrm{Ah}^{-0.5}$. Temperature dependence is implemented through Arrhenius equation, with $E_{\mathrm{a}, \text { Cyc, High T }}=$ $32699 \mathrm{~J} / \mathrm{mol}, E_{\mathrm{a}, \text { Cyc,Low T }}=55546 \mathrm{~J} / \mathrm{mol}$ :

$$
\begin{gathered}
k_{\text {Cyc,High T }}(T)=k_{\text {Cyc,High T,Ref }} \cdot \exp \left[\frac{-E_{\mathrm{a}, \text { Cyc }, \text { High T }}}{R_{g}}\left(\frac{1}{T}-\frac{1}{T_{\text {Ref }}}\right)\right] \\
k_{\text {Cyc,Low T }}\left(T, I_{\text {Ch }}=1 C\right) \\
=k_{\text {Cyc,Low T,Ref }} \cdot \exp \left[\frac{E_{\mathrm{a}, \text { Cyc,Low T }}}{R_{g}}\left(\frac{1}{T}-\frac{1}{T_{\text {Ref }}}\right)\right]
\end{gathered}
$$

Current rate dependence.-Current rate dependence for the lowtemperature mechanism is modeled via an exponential correlation with charge current, nominal cell capacity, and nominal current:

$$
\begin{aligned}
& k_{\text {Cyc,Low T }}\left(T=25^{\circ} C, I_{\mathrm{Ch}}\right) \\
& =k_{\text {Cyc,Low T,Ref }} \cdot \exp \left[\beta_{\text {Low T }} \cdot \frac{I_{\mathrm{Ch}}-I_{\mathrm{Ch}, \text { Ref }}}{C_{0}}\right]
\end{aligned}
$$

With nominal cell capacity $C_{0}=3 \mathrm{Ah}$, reference current $I_{\mathrm{Ch}, \mathrm{Ref}}=$ $3 \mathrm{~A}$, fitting gives $\beta_{\text {Low T }}=2.64 \mathrm{~h}$. In summary, the low temperature stress factor is calculated as follows:

$$
\begin{aligned}
& k_{\text {Cyc,Low T }}\left(T, I_{\mathrm{Ch}}\right)=k_{\mathrm{Cyc}, \text { Low T,Ref }} \cdot \exp \left[\frac{E_{\mathrm{a}, \text { Cyc,Low T }}}{R_{g}}\left(\frac{1}{T}-\frac{1}{T_{\text {Ref }}}\right)\right] \\
& \cdot \exp \left[\beta_{\text {Low T }} \cdot \frac{I_{\mathrm{Ch}}-I_{\mathrm{Ch}, \text { Ref }}}{C_{0}}\right]
\end{aligned}
$$

Figure 9a shows both stress factors correlations over temperature, with various current rates for the low-temperature mechanism. Figure $9 \mathrm{~b}$ shows the exponential correlation of current for the lowtemperature stress factor.

State of charge dependence.-The capacity loss attributed to the additional term for the mechanism at low temperatures at a high state of charge is calculated from experimental data of the CC-CV tests by subtraction of the previously developed terms of the calendar model and the cycle model for low and high temperature:

$$
\begin{aligned}
& Q_{\mathrm{L}, \text { Exp }, \text { Cycle,High SOC }} \\
&=Q_{\mathrm{L}, \mathrm{Exp}}-Q_{\mathrm{L}, \mathrm{Cal}}\left(T=\overline{T_{\mathrm{Exp}}}, S O C=50 \%, t=t_{\mathrm{Exp}}\right) \\
&-Q_{\mathrm{L}, \text { cyc,Low T }}\left(T=\overline{T_{\mathrm{Ch}, \mathrm{Exp}}}, I_{\mathrm{Ch}}=\overline{I_{\mathrm{Ch}, \mathrm{Exp}}}, Q_{\mathrm{Ch}}=Q_{\mathrm{Ch}, \mathrm{Exp}}\right) \\
&-Q_{\mathrm{L}, \mathrm{cyc}, \text { High T }}\left(T=\overline{T_{\mathrm{Exp}}}, Q_{\mathrm{Tot}}=Q_{\mathrm{Tot}, \mathrm{Exp}}\right)
\end{aligned}
$$

Charge throughput is factored in linearly, after reviewing the correlation of $Q_{\mathrm{L}, \text { Exp,Cycle, High soc. For the stress factor, additionally to the }}$ 


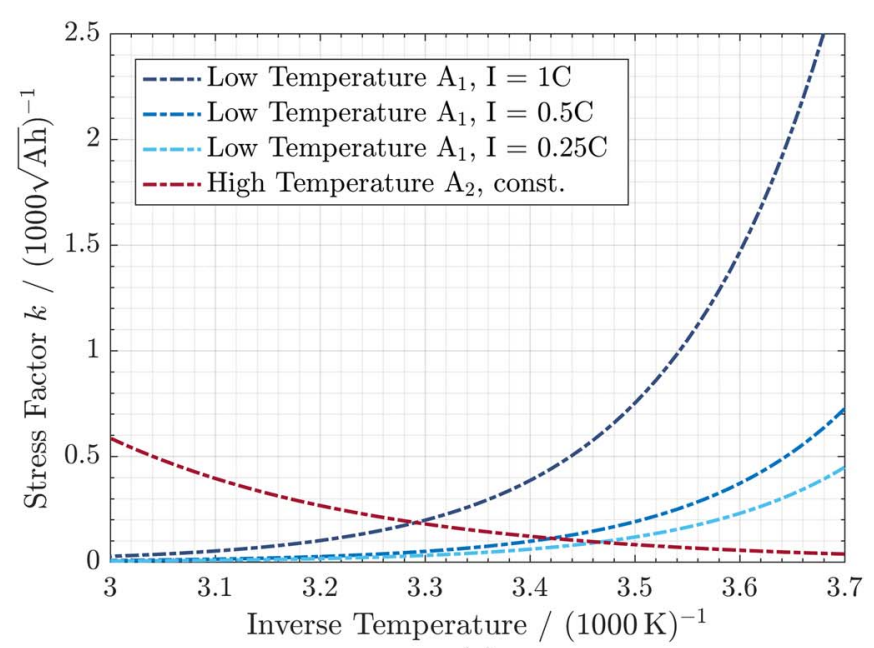

(a)

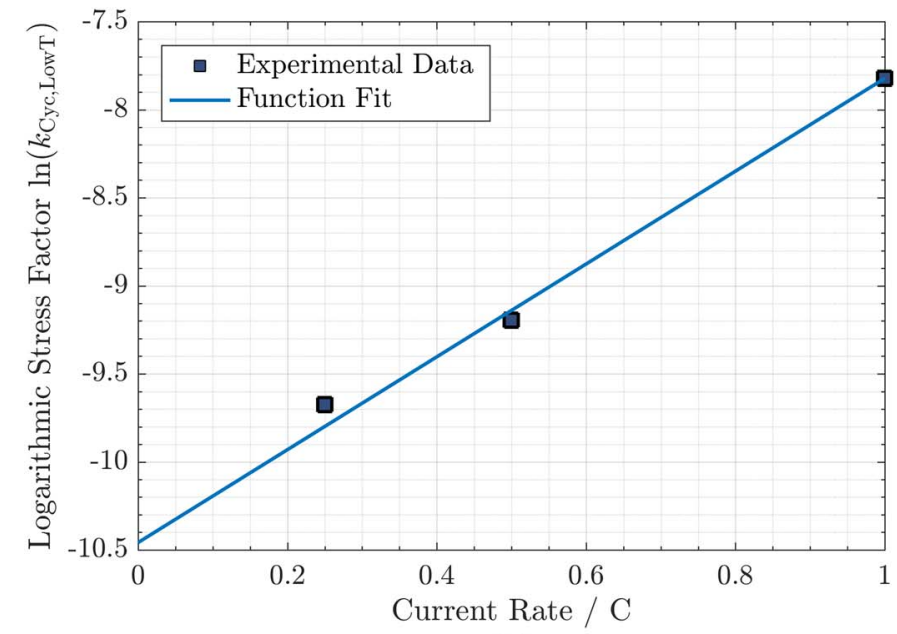

(b)

Figure 9. Current rate dependence of cold temperature effects in CC-Tests: a) Stress factor over temperature, b) Exponential correlation of low-temperature mechanism to charge current at $T=25^{\circ} \mathrm{C}$.

temperature and charge current dependence, a dependence for the SOC is implemented. The stress factor is only applied if the SOC lies above a fixed SOC limit $S O C_{\mathrm{Ref}}$, otherwise it set to zero:

$$
Q_{\mathrm{L}, \mathrm{cyc}, \text { Low T High SOC }}=k_{\mathrm{Cyc}, \text { Low T High SOC }}\left(T, I_{\mathrm{Ch}}, S O C\right) \cdot Q_{\mathrm{Ch}}
$$

$$
\begin{aligned}
k_{\text {Cyc,Low T High SOC }}\left(T, I_{\mathrm{Ch}}, S O C\right) \\
=k_{\text {Cyc,Low T High SOC,Ref }} \cdot \exp \left[\frac{E_{\mathrm{a}, \text { Cyc,Low T High SOC }}}{R_{g}}\left(\frac{1}{T}-\frac{1}{T_{\text {Ref }}}\right)\right] \\
\quad \cdot \exp \left[\beta_{\text {Low T High SOC }} \cdot \frac{I_{\mathrm{Ch}}-I_{\mathrm{Ch}, \text { Ref }}}{C_{0}}\right] \\
\quad\left(\frac{\operatorname{sgn}\left(S O C-S O C_{\mathrm{Ref}}\right)+1}{2}\right)
\end{aligned}
$$

Following this condition, only the charge throughput from experimental data which occurs in the tests above the SOC limit is considered for the fitting. Several cycles at the begin of the cycle tests were analyzed herefore: After disregarding cycles 1 to 3 at beginning of the cycling experiments due to changing conditions, cycles 4 to 10 were analyzed. Cell conditions after cycle 10 are similar to the analysis of these six cycles and are thus excluded from model parameterization to significantly reduce the efforts for parametrization. Temperature above the SOC limit is time averaged. The current value is averaged over the whole $\mathrm{CC}-\mathrm{CV}$ charge cycle and thus still dominated by the $\mathrm{CC}$ phase. As the current is variable during the $\mathrm{CV}$ phase, a charge throughput weighted-average current was calculated and used for fitting:

$$
\begin{aligned}
\overline{\bar{I}}_{\mathrm{Ch}, \operatorname{Exp}, S O C \geq 82 \%}= & \sum_{i} I_{\mathrm{Ch}, \operatorname{Exp}}\left(t=t_{i}\right) \\
& \cdot \frac{Q_{\mathrm{Ch}, \operatorname{Exp}}\left(t=t_{i}\right)-Q_{\mathrm{Ch}, \operatorname{Exp}}\left(t=t_{i}-1\right)}{Q_{\mathrm{Ch}, \operatorname{Exp}}}
\end{aligned}
$$

Results for the conditions (Charge throughput, current, and temperature) are then implemented during fitting the long-term tests featuring hundreds of cycles. With the reference stress factor $k_{\text {Cyc,Low T High SOC,Ref }}=2.031 \cdot 10^{-6} \mathrm{Ah}^{-1}\left(\right.$ at $\left.T=25^{\circ} \mathrm{C}, I_{\mathrm{Ch}}=3 \mathrm{~A}\right)$ fitting Equation 21 with the results from Equation 19 and 22 based on the CC-CV tests gives $E_{\mathrm{a}, \text { Cyc,Low T High SOC }}=2.3 \cdot 10^{5} \mathrm{~J} / \mathrm{mol}$, $\beta_{\text {Low T High SOC }}=7.8 \mathrm{~h}$ with $S O C_{\text {Ref }}=82 \%$. Figure $10 \mathrm{a}$ shows the low temperature, high SOC stress factor correlation to temperature and current. Figure 10b shows the exponential correlation. Current rate values are slightly below their respective constant current test values due to the lowered rate in the $\mathrm{CV}$ phase.

\section{Model Summary}

The proposed model for the calculation of cell capacity loss $Q_{\text {Loss }}$ through addition of the four capacity loss mechanisms is summarized as follows:

$$
\begin{aligned}
Q_{\mathrm{Loss}} & \left(T, S O C, I_{\mathrm{Ch}}, Q_{\mathrm{Tot}}, Q_{\mathrm{Ch}}\right) \\
= & Q_{\mathrm{L}, \mathrm{Cal}}(T, S O C, t)+Q_{\mathrm{L}, \text { Cyc }, \text { High T }}\left(T, Q_{\mathrm{Tot}}\right) \\
& +Q_{\mathrm{L}, \text { Cyc,Low T }}\left(T, I_{\mathrm{Ch}}, Q_{\mathrm{Ch}}\right) \\
& +Q_{\mathrm{L}, \text { Cyc,Low T High SOC }}\left(T, I_{\mathrm{Ch}}, S O C, Q_{\mathrm{Ch}}\right) \\
= & k_{\mathrm{Cal}}(T, S O C) \cdot \sqrt{t}+k_{\mathrm{Cyc}, \text { High T }}(T) \cdot \sqrt{Q_{\mathrm{Tot}}} \\
& +k_{\mathrm{Cyc}, \text { Low T }}\left(T, I_{\mathrm{Ch}}\right) \cdot \sqrt{Q_{\mathrm{Ch}}} \\
& +k_{\mathrm{Cyc}, \text { Low T High SOC }}\left(T, I_{C h}, S O C\right) \cdot Q_{\mathrm{Ch}}
\end{aligned}
$$

For the fitting process of the stress factors, averaged experimental conditions, e.g. temperature, are calculated to constant values for the respective test conditions. However, in prospected model applications, cell conditions are instead variable, e.g. for cell temperature due to variable heat generation and ambient temperature. Thus, a rate-based integral approach is used, as proposed by Thomas et al. ${ }^{30}$ The capacity loss for every time step with variable conditions is calculated. The integration variables $\tau$ and $\varphi$ are defined, replacing time $t$ and charge throughput $Q$ respectively:

$$
\begin{aligned}
Q_{\mathrm{Loss}}= & \int k_{\mathrm{Cal}}(T, S O C) \cdot\left(2 \tau^{0.5}\right)^{-1} d \tau \\
& +\int k_{\mathrm{Cyc}, \text { High T }}(T) \cdot\left(2 \varphi^{0.5}\right)^{-1} d \varphi_{\mathrm{Tot}} \\
& +\int k_{\mathrm{Cyc}, \text { Low T }}\left(T, I_{\mathrm{Ch}}\right) \cdot\left(2 \varphi^{0.5}\right)^{-1} d \varphi_{\mathrm{Ch}} \\
& +\int k_{\text {Cyc,Low T High SOC }}\left(T, I_{\mathrm{Ch}}, S O C\right) d \varphi_{\mathrm{Ch}}
\end{aligned}
$$

In conclusion, Table IV summarizes the model parameters and Figure 11 gives an overview of the stress factor correlations to cell conditions. 


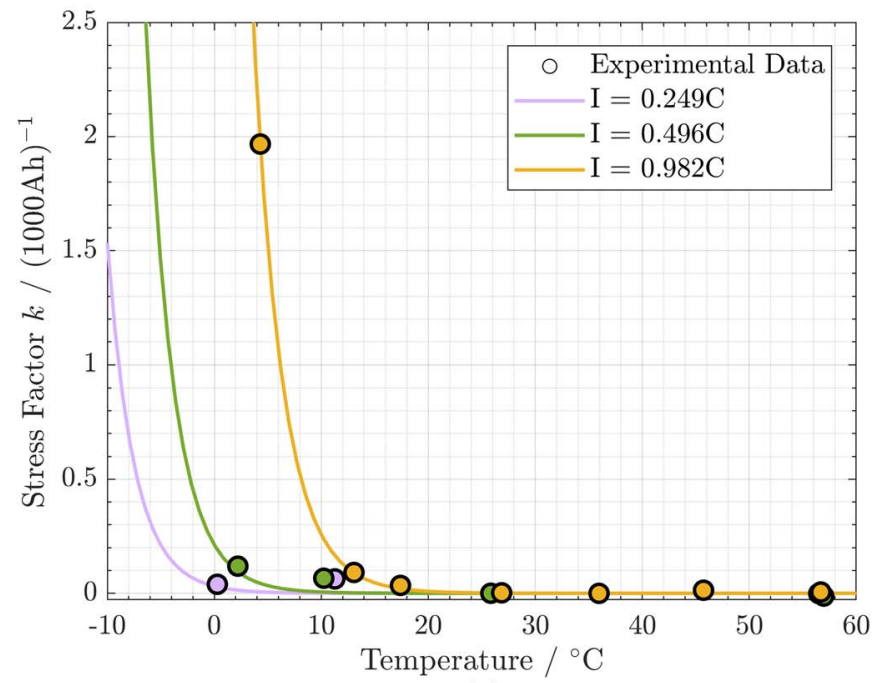

(a)

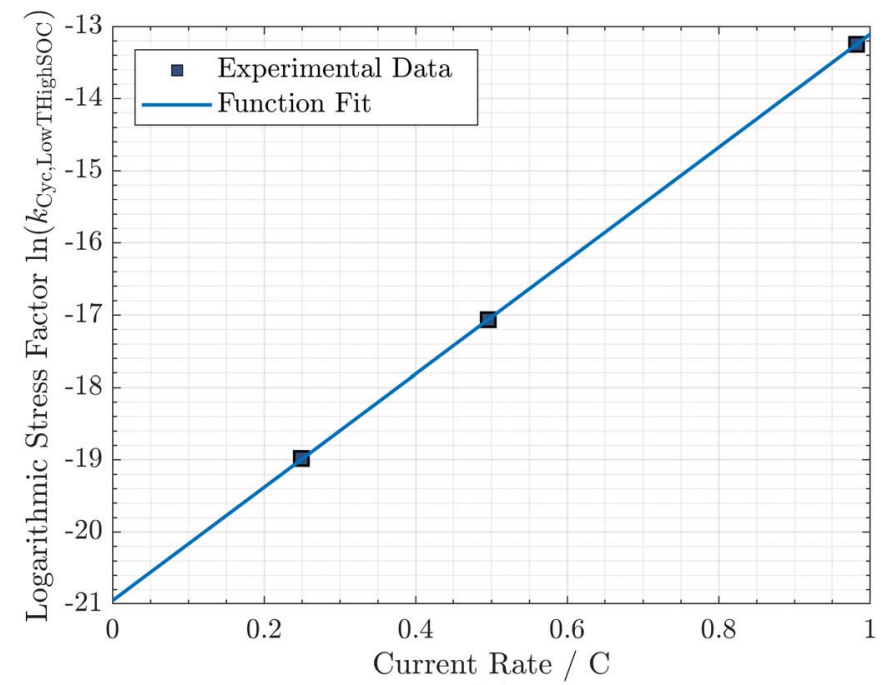

(b)

Figure 10. Current Rate Dependence of High State of Charge Temperature Effects in CC-CV tests: a) Stress factor over temperature, b) Exponential Dependence of stress factor on charge current at $T=25^{\circ} \mathrm{C}$.

\section{Model Validation}

Validation storage tests.-Figure 12 shows the validation of the storage tests at sample temperatures of $15^{\circ} \mathrm{C}$ (top) and $45^{\circ} \mathrm{C}$ (bottom). Of these data points, only the test points at $S O C=100 \%$ are previously included in the model parametrization, the remaining data points can be considered as new to the model.

Model results (lines) and experimental data (marker) are shown on the left side. For comparison between the model results and the experimental data, the model error is shown on the right side. The

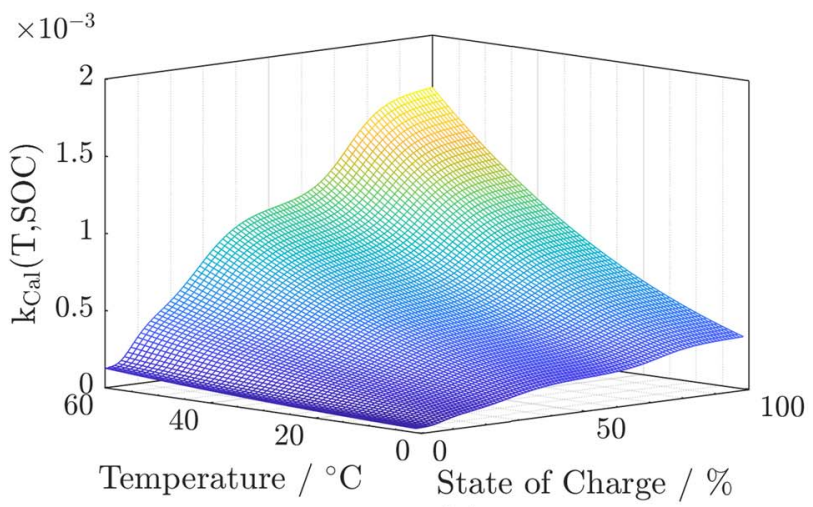

(a)

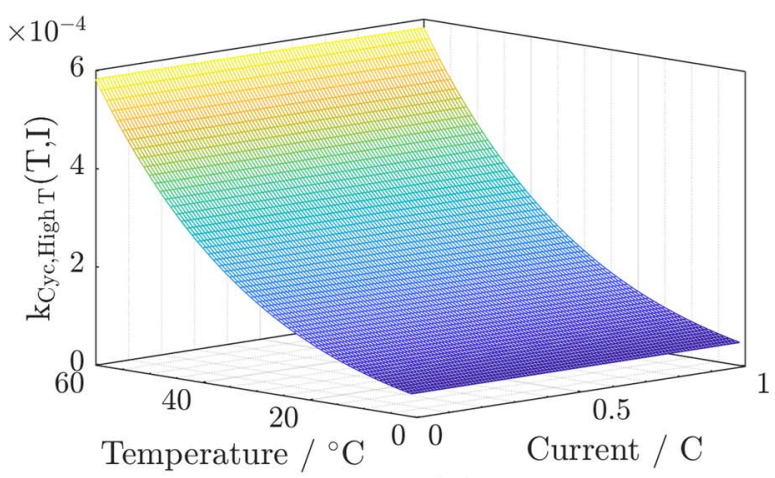

(c)

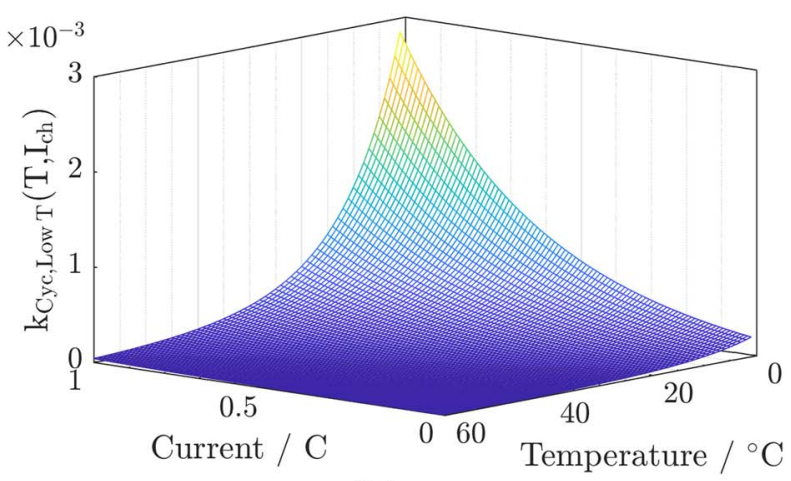

(b)

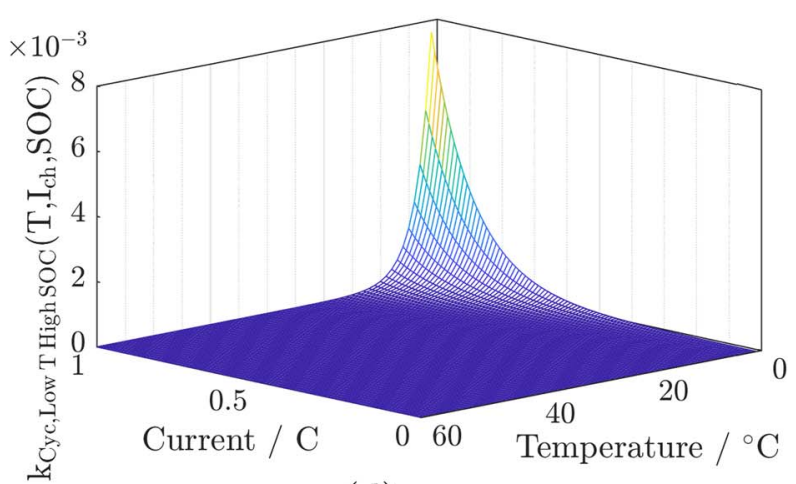

(d)

Figure 11. Overview of model stress factors: a) Calendar stress factor with temperature and State of Charge dependence (Unit: $\mathrm{h}^{-0.5}$ ), b) Cycle stress factor for low-temperature effects with charge current and temperature dependence (Unit: $\mathrm{Ah}^{-0.5}$ ), c) Cycle stress factor for high-temperature effects with temperature dependence (Unit: $\mathrm{Ah}^{-0.5}$ ), d) Cycle stress factor for low temperature/high state of charge effects with charge current rate and temperature dependence (Unit: $\mathrm{Ah}^{-1}$ ). Units for stress factors are not included in $\mathrm{z}$-axis legend but shown in the figure caption for clarity. 
Table IV. Summary of model parameters.

\begin{tabular}{lcc}
\multicolumn{1}{c}{ Model Parameter } & Value & Note \\
\hline$k_{\text {Cal,Ref }}$ & $3.69 \cdot 10^{-4} \cdot \mathrm{h}^{-0.5}$ & $T=25^{\circ} \mathrm{C}, S O C=50 \%$ \\
$k_{\text {Cyc, High T, Ref }}$ & $1.46 \cdot 10^{-4} \cdot \mathrm{Ah}^{-0.5}$ & $T=25^{\circ} \mathrm{C}, I=1 \mathrm{C}$ \\
$k_{\text {Cyc, Low T, Ref }}$ & $4.01 \cdot 10^{-4} \cdot \mathrm{Ah}^{-0.5}$ & $T=25^{\circ} \mathrm{C}, I_{\mathrm{Ch}}=1 \mathrm{C}$ \\
$k_{\text {Cyc,Low T High SOC,Ref }}$ & $2.03 \cdot 10^{-6} \mathrm{Ah}^{-1}$ & $T=25^{\circ} \mathrm{C}, I_{\mathrm{Ch}}=1 \mathrm{C}$ \\
$E_{\mathrm{a}, \text { Cal }}$ & $2.06 \cdot 10^{4} \mathrm{~J} / \mathrm{mol}$ & $S O C=100 \%$ \\
$E_{\mathrm{a}, \text { Cyc, High T }}$ & $3.27 \cdot 10^{4} \mathrm{~J} / \mathrm{mol}$ & $I=1 \mathrm{C}$ \\
$E_{\mathrm{a}, \text { Cyc,Low T }}$ & $5.55 \cdot 10^{4} \mathrm{~J} / \mathrm{mol}$ & $I_{\mathrm{Ch}}=1 \mathrm{C}$ \\
$E_{\mathrm{a}, \text { Cyc,Low T High SOC }}$ & $2.33 \cdot 10^{5} \mathrm{~J} / \mathrm{mol}$ & $I_{\mathrm{Ch}}=1 \mathrm{C}$ \\
$\alpha$ & $3.84 \cdot 10^{-1}$ & \\
$\beta_{\text {Low T }}$ & $2.64 \mathrm{~h}$ & \\
$\beta_{\text {Low T High SOC }}$ & $7.84 \mathrm{~h}$ & \\
$T_{\text {Ref }}$ & $298.15 \mathrm{~K}$ & \\
$I_{\text {Ch,Ref }}$ & $3 \mathrm{~A}$ & $S O C=50 \%$ \\
$U_{\mathrm{a}, \text { Ref }}$ & $1.23 \cdot 10^{-1} \mathrm{~V}$ & \\
$k_{0}$ & $1.42 \cdot 10^{-1}$ & See Appendix. \\
$U_{\mathrm{a}}$ & $U_{\mathrm{a}}(S O C)$ &
\end{tabular}

model error is calculated as:

$$
\text { Model Error }{ }_{\mathrm{i}}=\mathrm{Q}_{\text {Loss, } \mathrm{i}}-\text { QLoss,Exp,i }_{\mathrm{i}}
$$

This model error should not be confused with the relative model error, which is here not shown.

For the lower temperature, the lower capacity loss leads to smaller errors. At the higher temperatures, approximately twice the capacity loss occurs during the test period, leading to higher errors. Nonetheless, throughout the test period, the model error remains below $2 \%$.
Validation CC cycle tests.-Figure 13 shows the validation of the $\mathrm{CC}$ cycle tests through the calendar and the cycle aging mechanisms for high and low temperature, based on various averaged temperatures and current rates. Six test conditions are shown: Three different current rates at an ambient temperature of $0^{\circ} \mathrm{C}$ to show the model performance over the full current range, and three different ambient temperatures with a current rate of $1 \mathrm{C}$ to show the model performance over the full temperature range. Due to slightly varying cell conditions in the tests, multiple lines and experimental points are shown for some test points. For the model error (right), the value is averaged between the cells. For all cells except $0^{\circ} \mathrm{C}$ cycled at $1 \mathrm{C}$, the model error is below $2 \%$. The test point at $0^{\circ} \mathrm{C}$ cycled at $1 \mathrm{C}$ shows the highest aging gradient and peaks with a model error of $2.5 \%$ for two RPTs. At subsequent RPTs however, the model error decreases back to less than $1 \%$.

Validation CC-CV cycle tests.-Figure 14 shows the validation of the $\mathrm{CC}-\mathrm{CV}$ cycle tests through all aging mechanisms, based on the analyzed six cycles at various temperatures and current rates. Again, several test points at the lowest temperature, $0^{\circ} \mathrm{C}$, show the model performance for the considered current range. As the test point at $1 \mathrm{C}$ exhibits an increased model error of $2.8 \%$ at end of life, an additional test point with a current rate of $1.7 \mathrm{C}$ is tested and evaluated. The test point at $1.7 \mathrm{C}$, which even exceeds manufacturer specifications for the charge current, results in a model error of $0.8 \%$ at end of life, showing that the model can give good agreement with experimental data for high current rates. The two test points for higher temperatures are also in good agreement at the end of the tests.

Validation application-based dynamic current profile.-Figure 15 shows experimental data and model results for the dynamic current profile based on an application in a PV-residential battery system, as

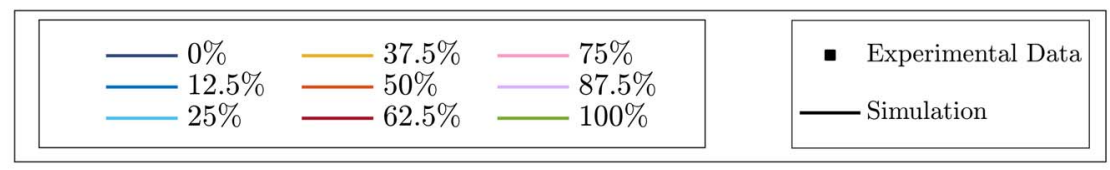

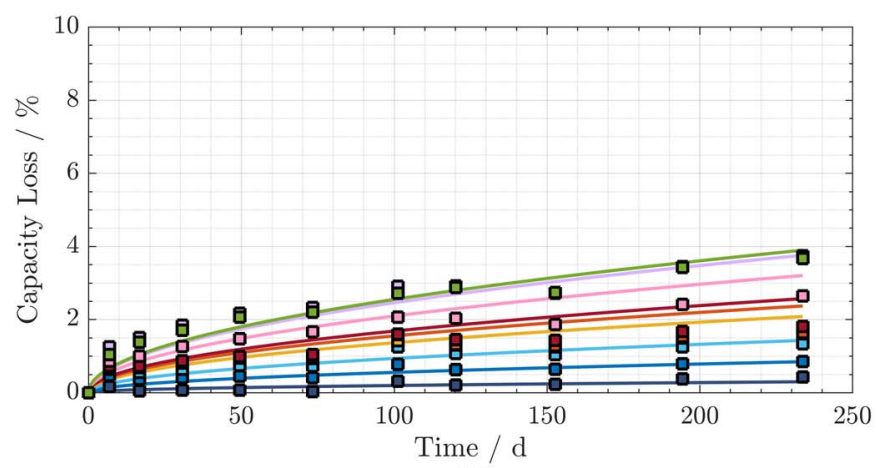

(a)

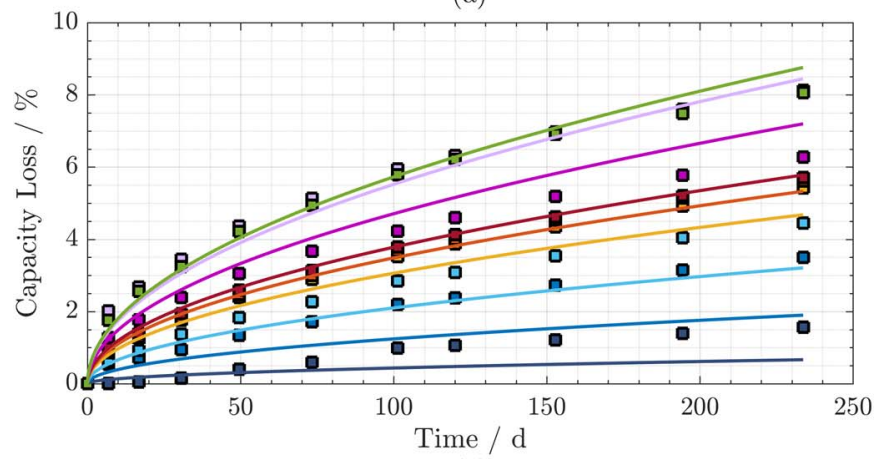

(c)

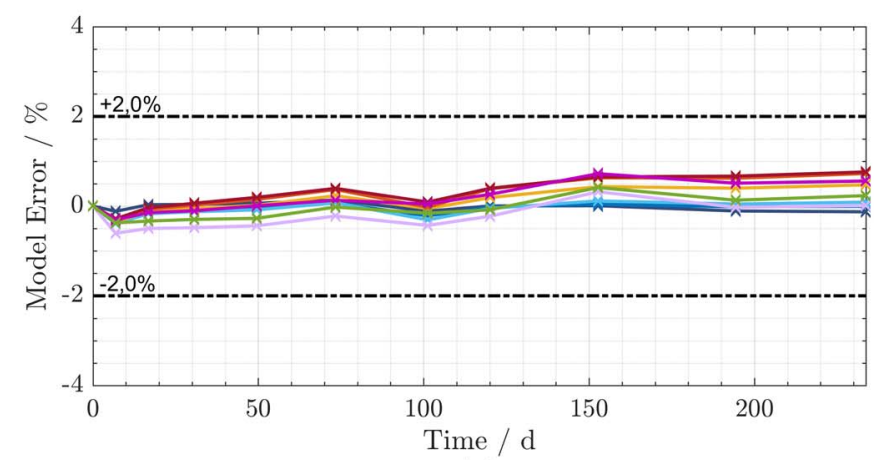

(b)

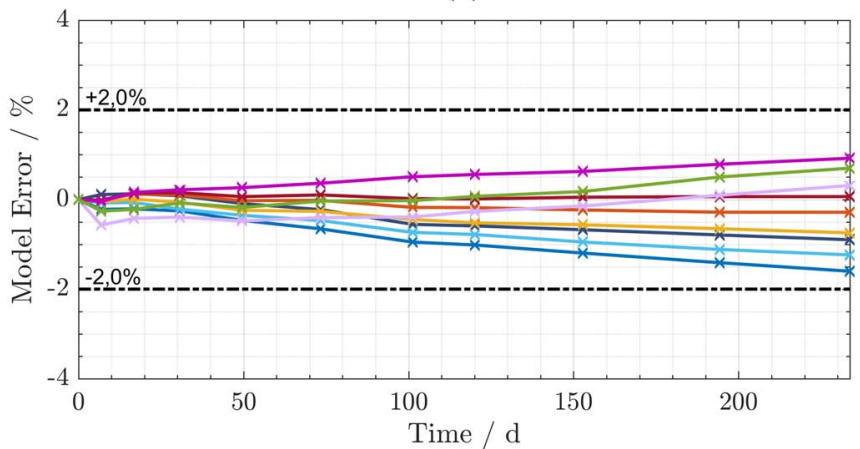

(d)

Figure 12. Comparison of model and experimental data for storage tests: a) Capacity loss at $T=15^{\circ} \mathrm{C}$, b) Model error at $T=15^{\circ} \mathrm{C}$, c) Capacity loss at $T=45^{\circ} \mathrm{C}, \mathrm{d}$ ) Model error at $T=45^{\circ} \mathrm{C}$. 


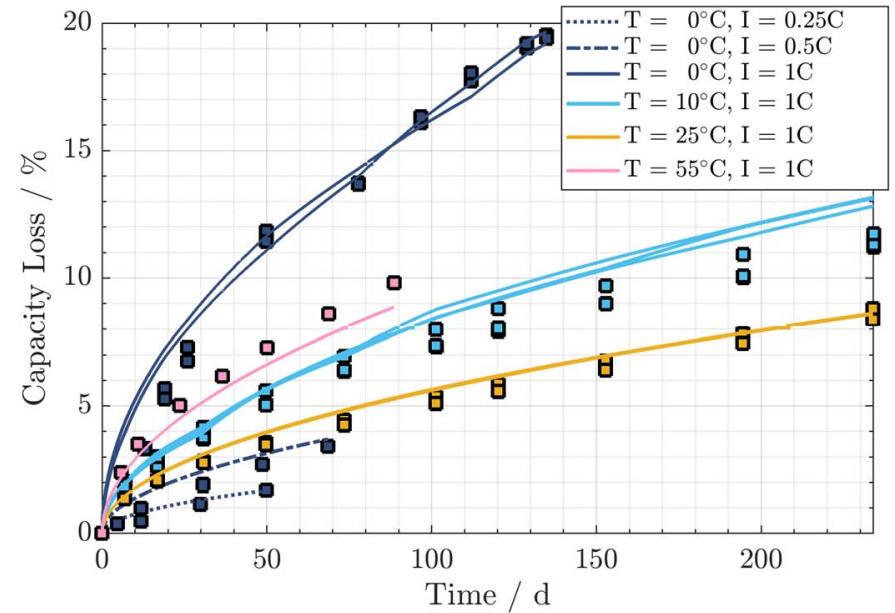

(a)

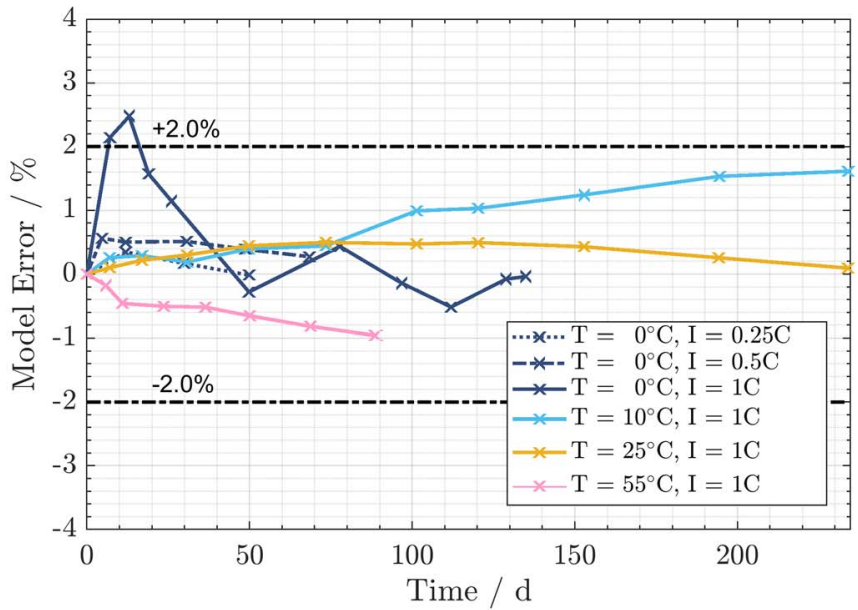

(b)

Figure 13. Comparison of model and experimental data for CC cycle tests: a) Capacity loss, b) Model error.

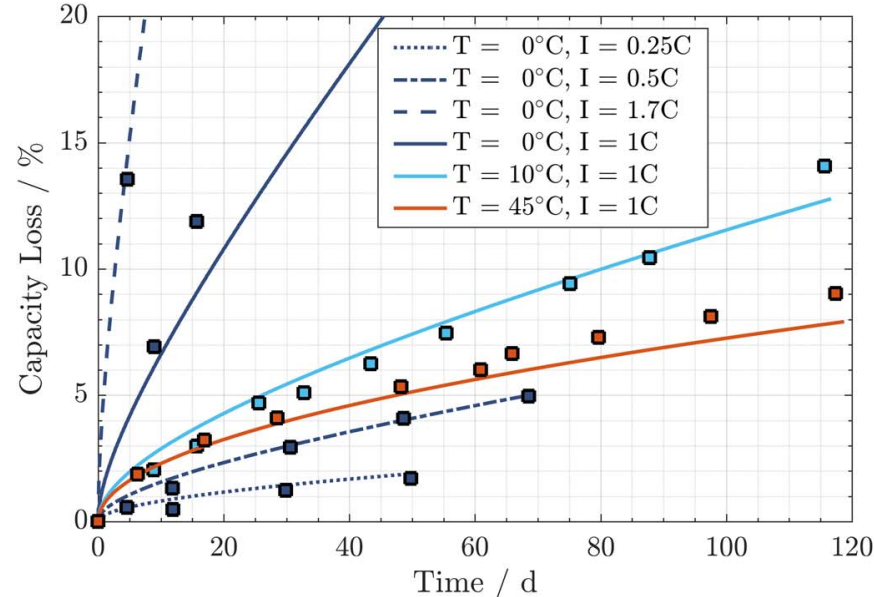

(a)

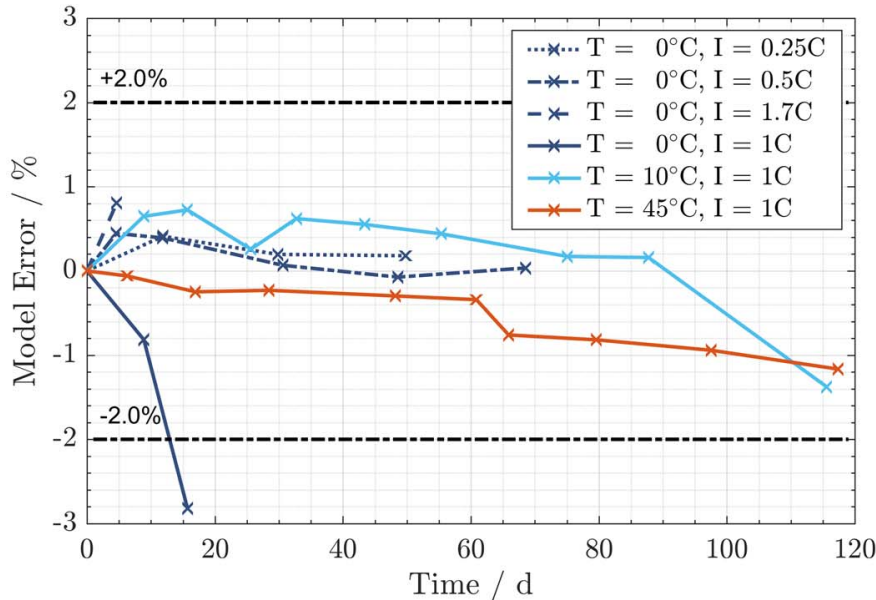

(b)

Figure 14. Comparison of model and experimental data for CC-CV cycle tests: a) Capacity loss, b) Model error.

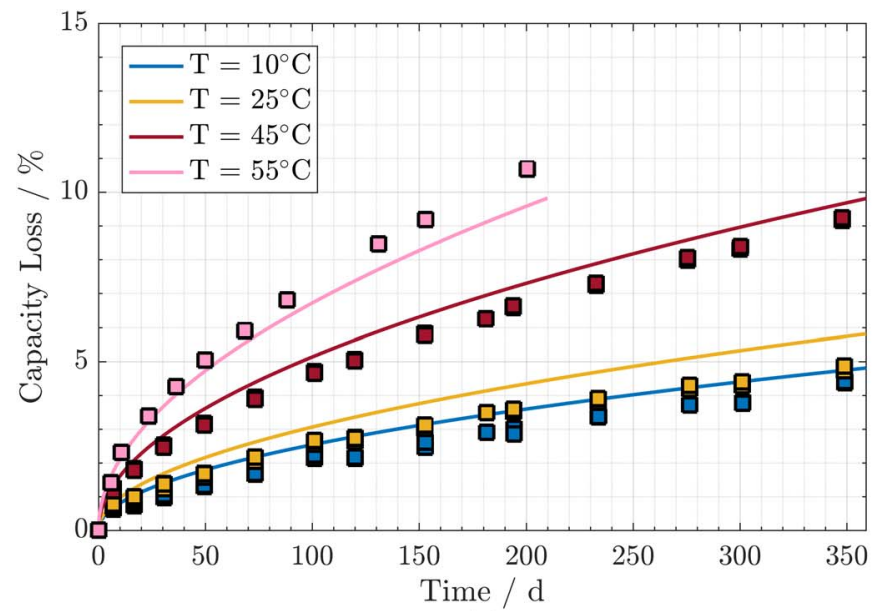

(a)

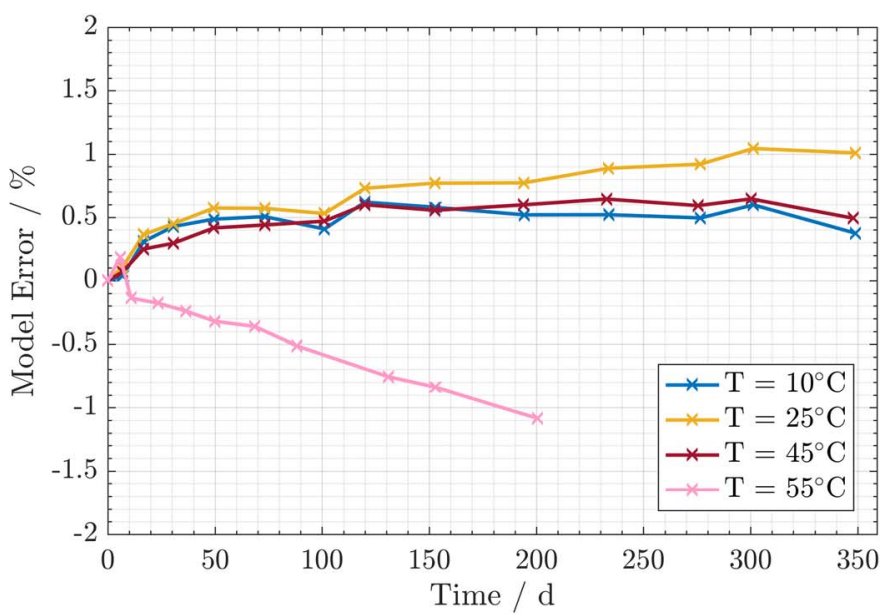

(b)

Figure 15. Comparison of model and experimental data for validation tests with PV-residential battery application profile: a) Capacity loss, b) Model error. 
was presented previously (see Figure 1). Test data for validation is continued for up to 114 days after the longest parametrization tests to a total of 348 days.

For $T=10^{\circ} \mathrm{C}, 25^{\circ} \mathrm{C}, 45^{\circ} \mathrm{C}$ the model shows a slight overprediction of capacity loss, whereas at $T=55^{\circ} \mathrm{C}$ the model shows a trend towards underprediction. The trend for the overprediction at $T=10^{\circ} \mathrm{C}, 25^{\circ} \mathrm{C}, 45^{\circ} \mathrm{C}$ is apparent along the whole test period, but levels off in the last RPT. The underprediction trend at $T=55^{\circ} \mathrm{C}$ shows no leveling off. It should be noted though, that at $T=55^{\circ} \mathrm{C}$ only a single cell is tested. For $T=10^{\circ} \mathrm{C}, 25^{\circ} \mathrm{C}, 45^{\circ} \mathrm{C}$, the model errors are below $1 \%$ of the original cell capacity at the end of the test period. At $T=55^{\circ} \mathrm{C}$ the model error is at $\approx 1 \%$ after $\approx 200$ days. For the validation tests after 348 days, the relative model error, defined as $\left(Q_{\text {Loss,i }}-Q_{\text {Loss,Exp,i }}\right) / Q_{\text {Loss,Exp,i }}$, is at the highest value of $+21 \%$ at $T=25^{\circ} \mathrm{C}$

The validation tests with a test duration of 348 days reached approximately 539 profile repetitions. As one profile repetition is an accelerated representation of a winter and a summer day (see Section Experimental Methods), this gives accelerated test results for 1078 days or approximately 3 years of operation of the representative system.

Summarized, the model results are in good agreement with the tests and validate the model performance in variable current applications, which have not been used for the model parameterization. Furthermore, the model shows good performance in the additional timeframe beyond parametrization, as well as at current loads with varying cycle depths.

Previous constant current cycle tests at $1 \mathrm{C}$ showed a minimum for the capacity loss for a temperature of $25^{\circ} \mathrm{C}$ (see Figure 5). The experimental and model results for the dynamic current profile instead show a minimum for the capacity loss at $10^{\circ} \mathrm{C}$ for the investigated conditions and increasing capacity loss with higher temperatures. The model results give insight that here the calendar aging-induced capacity loss is the dominant mechanism. The overall cycle induced capacity loss is comparably less due to the low average/maximum C-rates (see Table III). The model, therefore, predicts the trend for the influence of the operating temperature here accurately.

\section{Conclusions}

This article presents a comprehensive semi-empirical model approach for the capacity loss of lithium-ion batteries. The approach is based on a reduced set of internal cell parameters and physically supported degradation functions. For parameterization, a lifetime test study with lithium iron phosphate cells is conducted, including storage and cycle tests.

State of Charge dependence of the calendar aging is implemented through coupling the anode open circuit potential in a Tafel equation based approach. Temperature dependence of calendar aging is calculated with Arrhenius equation.

For the cycle aging, the emphasis is placed on the varying degradation at different temperatures. Three cycle aging correlations are identified and correlated to two physical cell internal degradation effects: Lithium loss due to transport limitations, possibly lithium plating, during charging at low temperature and increased SEI growth due to cycling at high temperature. Degradation is separated under different conditions: High temperature, low temperature, and low temperature at a high state of charge. Current rate dependence and State of Charge dependence is implemented where observed. Cycle aging is correlated with the charge throughput. No direct correlation with the cycle depth is implemented, but cycle operation at high SOC leads to an increased capacity loss in the cycle model.

For model validation, a comparison of the simulation results with the aging model to the experimental data is evaluated. The model application in a stationary storage real-world scenario based on the application in a PV-residential battery system is tested via additional profiles, which have not been used for model parameterization and feature varying cycle depth. Tests are continued for up to 114 days beyond the longest parametrization tests to a total duration of 348 days.

Both the parameterization tests, as well as dynamic current tests exclusively used for validation, are in good agreement with the model results. At the end of the dynamic current profile validation tests between $10^{\circ} \mathrm{C}$ and $45^{\circ} \mathrm{C}$, after 348 days, the model error is below $1 \%$ of the original cell capacity and the maximum relative error for the capacity loss is below $21 \%$. The optimum temperature for a minimum of capacity loss is also shown to be accurately predicted.

\section{Outlook}

Additional validation tests covering more application scenarios and/or stronger variation of test conditions, such as a dynamic ambient temperature or a non-repeating current profile can further support the assessment of the model performance for real-world applications.

Future work involves the model application in system simulations of stationary battery storage systems. Here, the model can be used for lifetime evaluation of various applications.

Through coupling with thermal pack and system models, the thermal management can be evaluated. I.e. the impact of thermal pack gradients and cooling setups over the system lifetime can be calculated. On the system level, the system temperature or thermal control strategies can be analyzed and subsequently optimized.

The model can also serve to develop operational strategies for the energy management system, in order to reduce cell degradation by avoiding high-stress factor conditions, i.e. high SOC for long storage durations and high current rates at a high state of charge.

Although the cell impedance was not identified as critical for the cell end-of-life criteria, the increase can be evaluated towards how it affects the thermal management and system energy efficiency over the lifetime.

\section{Acknowledgments}

The research project Intelligent Home Energy Management (IHEM) is funded by the Federal Ministry for Economic Affairs and Energy within the Funding initiative Electrical Storages (grant number 03ET1205G) and cared by Project Management Jülich. The authors also thank the Bavarian Ministry of Economic Affairs and Media, Energy and Technology for their support via the EEBatt project. K. Smith wishes to acknowledge support by the Vehicle Technologies Office, Office of Energy Efficiency and Renewable Energy, U. S. Department of Energy (DOE) under DOE Contract No. DE-AC3608GO28308 with the National Renewable Energy Laboratory. The authors thank S. Santhanagopalan for the highly helpful discussions. The responsibility for the content of this publication lies with the author.

\section{Appendix}

Data for the open circuit potential of the lithium graphite anode $U_{a}$ as a function of the degree of lithiation $\mathrm{x}_{\mathrm{a}}$ is taken from Safari et al.: ${ }^{28}$

$$
\begin{aligned}
U_{\mathrm{a}}\left(x_{\mathrm{a}}\right)= & 0.6379+0.5416 \cdot \exp \left(-305.5309 \cdot x_{\mathrm{a}}\right)+0.044 \tanh \left(-\frac{x_{\mathrm{a}}-0.1958}{0.1088}\right) \\
& -0.1978 \tanh \left(\frac{x_{\mathrm{a}}-1.0571}{0.0854}\right)-0.6875 \tanh \left(\frac{x_{\mathrm{a}}+0.0117}{0.0529}\right) \\
& -0.0175 \tanh \left(\frac{x_{\mathrm{a}}-0.5692}{0.0875}\right)
\end{aligned}
$$

Anode stoichiometry $x_{\mathrm{a}}$ is calculated as function of the SOC of the full-cell by linearly interpolating between $S O C=0 \%$ and $S O C=100 \%$ :

$$
x_{\mathrm{a}}(S O C)=x_{\mathrm{a}}(S O C=0 \%)+S O C \cdot\left[x_{\mathrm{a}}(S O C=100 \%)-x_{\mathrm{a}}(S O C=0 \%)\right]
$$

The degree of lithiation at $S O C=0 \%$, respectively $S O C=100 \%$, is derived from fitting the half-cell open circuit potentials of both electrodes in combination with cell parameters to measured full-cell open circuit potential data. 
Table AI. Cell parameters used for fitting half-cell open circuit potentials to full-cell open circuit potential from experimental data. Experimental data values refer to existing cell dissection experiments.

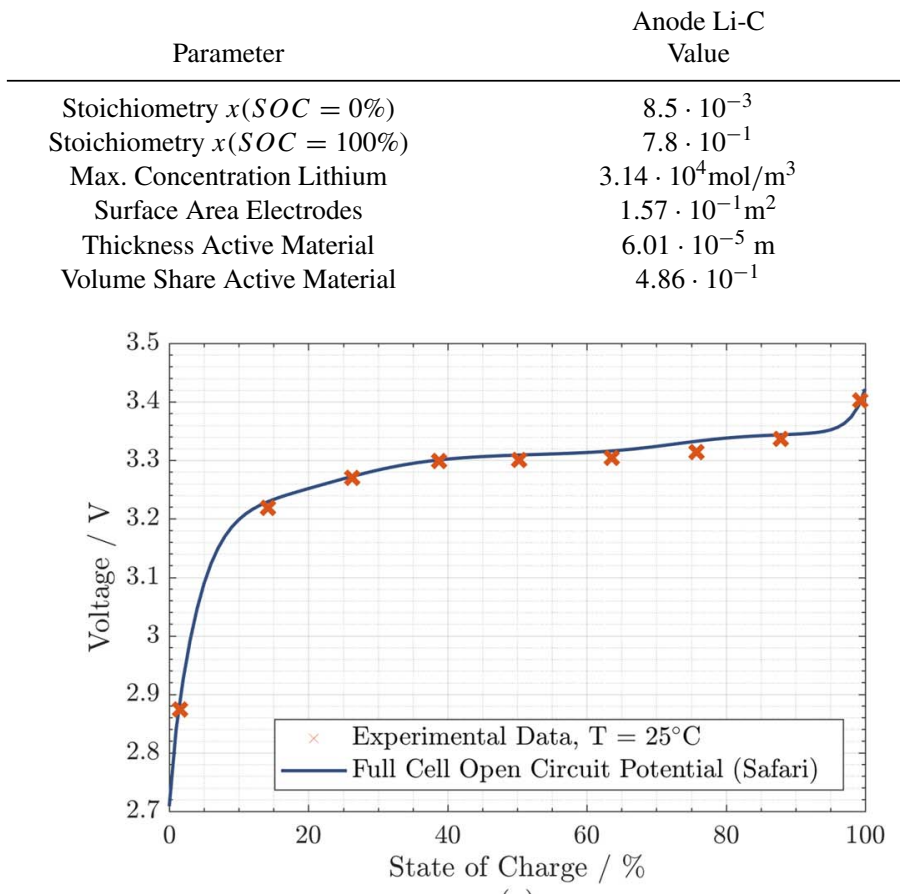

(a)
Cathode $\mathrm{LiFePO}_{4}$

Reference

Value

$\begin{array}{cc}9.16 \cdot 10^{-1} & \text { Fit } \\ 4.5 \cdot 10^{-2} & \text { Fit } \\ 2.28 \cdot 10^{4} \mathrm{~mol} / \mathrm{m}^{3} & 28 \\ 1.57 \cdot 10^{-1} \mathrm{~m}^{2} & \text { Exp. } \\ 7.90 \cdot 10^{-5} \mathrm{~m} & \text { Exp. } \\ 4.55 \cdot 10^{-1} & \text { Fit }\end{array}$

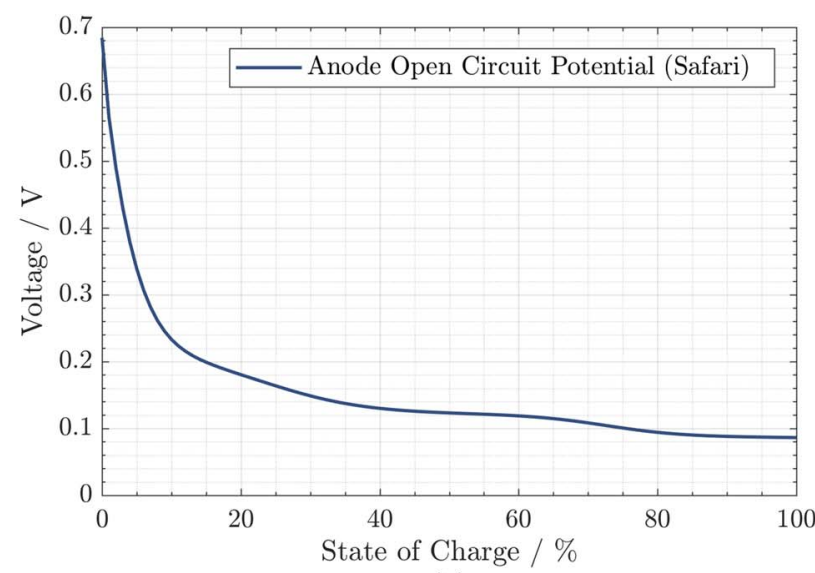

(b)

Figure A1. Open Circuit Potentials: a) Comparison of full-cell open circuit potential reconstructed from half-cell potentials against experimental data, b) Anode open circuit potential over the full-cell operating range.

Open circuit potential data for the lithium iron phosphate cathode $\left(\mathrm{LiFePO}_{4}\right) \mathrm{U}_{\mathrm{c}}\left(x_{\mathrm{c}}\right)$ is also taken from Safari et al.:28

$$
\begin{aligned}
U_{\mathrm{c}}\left(x_{\mathrm{c}}\right)= & 3.4323-0.8428 \cdot \exp \left[-80.2493 \cdot\left(1-x_{\mathrm{c}}\right)^{1.3198}\right] \\
& -3.2474 \cdot 10^{-6} \cdot \exp \left[20.2645 \cdot\left(1-x_{\mathrm{c}}\right)^{3.8003}\right] \\
& +3.2482 \cdot 10^{-6} \cdot \exp \left[20.2646 \cdot\left(1-x_{\mathrm{c}}\right)^{3.7995}\right]
\end{aligned}
$$

The chosen parameters for fitting the half-cell open circuit potential to experimental full-cell data - measured, fitted or taken from literature - are given in Table AI.

Electrode surface area and active material thickness are chosen from existing experiments based on cell dissection. Stoichiometry and active material volume share values are fitted to the experimental full-cell open circuit potential, shown in Figure A1a. Figure A1b shows the corresponding anode open circuit potential over the full-cell state of charge, calculated with Equations A1 and A2.

\section{ORCID}

M. Schimpe (1) https://orcid.org/0000-0001-5000-2045

\section{References}

1. M. Munsell, Greentech Media (07.03.2017).

2. C. Patsios, B. Wu, E. Chatzinikolaou, D. J. Rogers, N. Wade, N. P. Brandon, and P. Taylor, Journal of Energy Storage, 5, 48 (2016).

3. X. Jin, A. Vora, V. Hoshing, T. Saha, G. Shaver, R. E. García, O. Wasynczuk, and S. Varigonda, Journal of Power Sources, 342, 750 (2017).

4. C. Delacourt and M. Safari, Journal of the Electrochemical Society, 159(8), A1283 (2012).

5. E. Sarasketa-Zabala, I. Gandiaga, L. M. Rodriguez-Martinez, and I. Villarreal, Journal of Power Sources, 272, 45 (2014).

6. S. Grolleau, A. Delaille, H. Gualous, P. Gyan, R. Revel, J. Bernard, E. Redondo-Iglesias, and J. Peter, Journal of Power Sources, 255, 450 (2014).

7. E. Sarasketa-Zabala, I. Gandiaga, E. Martinez-Laserna, L. M. Rodriguez-Martinez, and I. Villarreal, Journal of Power Sources, 275, 573 (2015).

8. J. Wang, P. Liu, J. Hicks-Garner, E. Sherman, S. Soukiazian, M. Verbrugge, H. Tataria, J. Musser, and P. Finamore, Journal of Power Sources, 196(8), 3942 (2011).
9. J. Schmalstieg, S. Käbitz, M. Ecker, and D. U. Sauer, Journal of Power Sources, 257, 325 (2014).

10. M. Swierczynski, D.-I. Stroe, A.-I. Stan, R. Teodorescu, and S. K. Kaer, IEEE Trans. on Ind. Applicat., 51(4), 3453 (2015).

11. E. Sarasketa-Zabala, E. Martinez-Laserna, M. Berecibar, I. Gandiaga, L. M. Rodriguez-Martinez, and I. Villarreal, Applied Energy, 162, 839 (2016).

12. M. Ecker, J. B. Gerschler, J. Vogel, S. Käbitz, F. Hust, P. Dechent, and D. U. Sauer, Journal of Power Sources, 215, 248 (2012).

13. T. Waldmann, M. Wilka, M. Kasper, M. Fleischhammer, and M. Wohlfahrt-Mehrens, Journal of Power Sources, 262, 129 (2014).

14. M. Naumann, R. C. Karl, C. N. Truong, A. Jossen, and H. C. Hesse, Energy Procedia, 73, 37 (2015)

15. C. N. Truong, M. Naumann, R. C. Karl, M. Müller, A. Jossen, and H. C. Hesse, Batteries, 2(2), 14 (2016).

16. A. Zeh, M. Müller, M. Naumann, H. C. Hesse, A. Jossen, and R. Witzmann, Batteries, 2(3), 29 (2016).

17. Masayuki Yasuda, in OREBA 1.0 - International Conference on Olivines for Rechargeable Batteries, (2014).

18. M.-k. Konan, SONY US26650FTC1 Product Specification, (2010).

19. H.-P. Beck, Project Report ESPEN - Potentials of electrochemical storages in power grids in competition to further technologies and system solutions.

20. S. F. Schuster, T. Bach, E. Fleder, J. Müller, M. Brand, G. Sextl, and A. Jossen, Journal of Energy Storage, 1, 44 (2015).

21. M. Ecker, N. Nieto, S. Käbitz, J. Schmalstieg, H. Blanke, A. Warnecke, and D. U. Sauer, Journal of Power Sources, 248, 839 (2014).

22. J. Vetter, P. Novák, M. R. Wagner, C. Veit, K.-C. Möller, J. O. Besenhard, M. Winter, M. Wohlfahrt-Mehrens, C. Vogler, and A. Hammouche, Journal of Power Sources, 147(1-2), 269 (2005).

23. A. Barré, B. Deguilhem, S. Grolleau, M. Gérard, F. Suard, and D. Riu, Journal of Power Sources, 241, 680 (2013).

24. M. Broussely, P. Biensan, F. Bonhomme, P. Blanchard, S. Herreyre, K. Nechev, and R. J. Staniewicz, Journal of Power Sources, 146(1-2), 90 (2005).

25. K. Smith, A. Saxon, M. Keyser, B. Lundstrom, Z. Cao, and A. Roc, in 2017 American Control Conference (ACC), p. 4062, IEEE (2017).

26. S. Santhanagopalan, K. Smith, J. Neubauer, G.-H. Kim, A. Pesaran, and M. Keyser, Design and analysis of large lithium-ion battery systems, Artech House (2014).

27. P. Keil, S. F. Schuster, J. Wilhelm, J. Travi, A. Hauser, R. C. Karl, and A. Jossen, J. Electrochem. Soc., 163(9), A1872-A1880 (2016).

28. M. Safari and C. Delacourt, Journal of the Electrochemical Society, 158(5), A562 (2011).

29. M. Petzl, M. Kasper, and M. A. Danzer, Journal of Power Sources, 275, 799 (2015).

30. E. V. Thomas, I. Bloom, J. P. Christophersen, and V. S. Battaglia, Journal of Power Sources, 206, 378 (2012). 